\title{
A Roadmap for Tailoring the Strength and Ductility of Ferritic/Martensitic T91 Steel via Thermo-mechanical Treatment
}

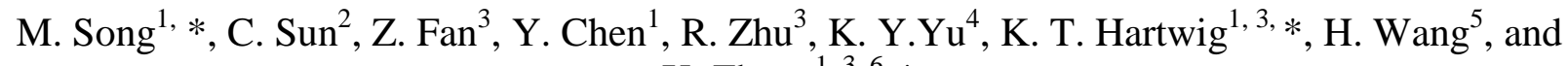 \\ X. Zhang ${ }^{1,3,6, *}$ \\ ${ }^{1}$ Department of Materials Science and Engineering, Texas A\&M University, College Station, \\ TX 77843, USA \\ ${ }^{2}$ Materials Science and Technology Division, Los Alamos National Laboratory, Los Alamos, \\ NM87545, USA \\ ${ }^{3}$ Department of Mechanical Engineering, Texas A\&M University, College Station, TX 77843- \\ 3123, USA \\ ${ }^{4}$ Department of Materials Science and Engineering, China University of Petroleum-Beijing, \\ Beijing 102249, China \\ ${ }^{5}$ Department of Electrical Engineering, Texas A\&M University, College Station, TX 77843-3128, \\ USA \\ ${ }^{6}$ School of Materials Engineering, Purdue University, West Lafayette, IN 47907, USA \\ *Corresponding authors: X. Zhang, zhangx@tamu.edu; K. T. Hartwig, thartwig@tamu.edu; \\ Miao Song, meowsong@umich.edu; \\ Abstract:
}

Ferritic/martensitic (F/M) steels with high strength and excellent ductility are important candidate materials for the life extension of the current nuclear reactors and the design of next generation nuclear reactors. Recent studies show that equal channel angular extrusion (ECAE) was able to improve mechanical strength of ferritic T91 steels moderately. Here, we examine several strategies to further enhance the mechanical strength of T91 while maintaining its ductility. Certain thermo-mechanical treatment (TMT) processes enabled by combinations of ECAE, water quench, and tempering may lead to "ductile martensite" with exceptionally high strength in T91 steel. The evolution of microstructures and mechanical properties of T91 steel were investigated in detail, and transition carbides were identified in water quenched T91 steel. This study provides guidelines for tailoring the microstructure and mechanical properties of T91 steel via ECAE enabled TMT for an improved combination of strength and ductility. 
Keywords: T91 steel (9Cr-1Mo steel or Grade 91); ECAE or ECAP; thermo-mechanical treatment (TMT); mechanical properties; microstructure;

\section{Introduction}

The design of next generation nuclear reactors requires the development of advanced materials that can maintain structural integrity in harsh radiation environments. Structural materials in advanced nuclear reactors need to sustain significant radiation dose, over 100 displacements-per-atom (dpa), cyclic variation of thermal stress, and be resistant to oxidation, corrosion, and radiation creep over 60 years[1]. Ferritic/martensitic (F/M) steels containing 9-12 wt.\% $\mathrm{Cr}$ are considered as major candidates for advanced nuclear reactors because this family of F/M steels exhibits better resistance to swelling, and irradiation assisted stress corrosion cracking (IASCC), and has less transmutation issues compared to austenitic stainless steels [2-4]. T91 steel is a commercialized F/M steel, which is modified from T9 (9Cr-1Mo) steel by the addition of $\mathrm{V}, \mathrm{Nb}$, and $\mathrm{N}$ [5]. As a representative of second generation structural materials for the power industry, T91 steel has been used as structural materials for steam generators, pressure vessels, and piping systems [6].

The mechanical properties of these advanced steels are critical for practical applications. Several approaches have been used to enhance the strength of F/M steels [7-9], among which grain boundary induced strengthening is promising. Equal channel angular extrusion (ECAE) is a widely used severe plastic deformation (SPD) technique to refine the grain size of bulk metallic materials [10]. During ECAE, severe shear strain (up to $2-4 \mathrm{~mm} / \mathrm{mm}$ ) is often introduced into a bulk material by extrusion through a channel of constant cross section that contains an abrupt angle. Consequently, the average grain sizes of numerous metallic materials can be refined to several hundred nm $[11,12]$. Recently, this technique has been applied to reactor steels and their model alloys, such as F/M T91 [13-15], austenitic Fe-Cr-Ni [16-18], and oxide-dispersionstrengthened (ODS) steels [19, 20]. When the average grain size of T91 steel is refined by over an order of magnitude down to $300 \mathrm{~nm}$, its hardness is increased by 70\% [13]. Simultaneously, the refined microstructure shows enhanced radiation tolerance [21-23].

The metallic materials processed by ECAE and similar SPD techniques commonly show high strength, but limited ductility[24]. Thermo-mechanical treatments (TMT) are frequently applied to pure metals or alloys to achieve a combination of high strength and ductility or 


\section{Experiments}

The chemical composition (in wt.\%) of T91 alloy used in this study is shown in Table 1. The as-received (AR) T91 steel was heat-treated by a standard normalization $\left(1038^{\circ} \mathrm{C}\right.$ for $0.5 \mathrm{~h}$ with air cooling) and tempering $\left(760^{\circ} \mathrm{C}\right.$ for $0.5 \mathrm{~h}$ and air cooling) procedure same as described in the literature [40]. Annealing of AR T91 at $800{ }^{\circ} \mathrm{C}$ for $1 \mathrm{~h}$, followed by furnace cooling, results 
in as-annealed (AA) T91. The AA T91 was fully tempered and contained the predominately ferrite phase. Billets with dimensions of $25.4 \times 25.4 \times(50.8 \sim 127) \mathrm{mm}$ were cut from AR materials for further processing. The TMT processes adopted in this study as shown in Fig.1 via a flow chart include: (1) austenitizing at $800 \sim 1200^{\circ} \mathrm{C}$ (with an interval of $100^{\circ} \mathrm{C}$ ) for $1 \mathrm{~h}$ followed by quenching in ice water; (2) ECAE process of austenite at $1000^{\circ} \mathrm{C}$ followed by water quenching, followed by tempering the thus-deformed T91 steel for $1 \mathrm{~h}$ at $300-800^{\circ} \mathrm{C}$; (3) tempering the water quenched specimens at $500{ }^{\circ} \mathrm{C}$ for $10 \mathrm{~h}$, followed by ECAE of the tempered specimens at $300^{\circ} \mathrm{C}$. The TMT processed materials were then subjected to microstructure characterizations and mechanical testing.

The austenization experiments were performed in a box furnace with a maxiumum temperature capability of $1300 \pm 10^{\circ} \mathrm{C}$. ECAE processing was carried out on an MTS-controlled hydraulic press with 225 ton $\left(2.22 \times 10^{3} \mathrm{kN}\right)$ force capacity. Prior to the ECAE of T91, billets were heated to $1000^{\circ} \mathrm{C}$ for $1 \mathrm{~h}$ to achieve the complete austenite phase, extruded at a rate of 25.4 $\mathrm{mm} / \mathrm{s}$, and then quickly water quenched. Although the die was kept at $300^{\circ} \mathrm{C}$, the fast extrusion rate was applied to maintain the temperature of the billets close to $1000^{\circ} \mathrm{C}$, so that minimum phase transformation occurred during the extrusion. Post-processing heat treatments in a range of $300 \sim 800^{\circ} \mathrm{C}$ were carried out in a quartz tube with the protection of ultra-high purity Ar gas flow, and then cooled by flowing Ar. The identifiers of samples with indication of their TMT history are summarized in Table 2.

Dogbone-shaped tensile specimens with gauge dimensions of $8 \times 3 \times 1 \mathrm{~mm}$ were cut from the inner part of the water quenched or ECAE processed billets using the electro discharge machining (EDM) technique. Samples were electro-polished to remove the porous oxide layer left by EDM, prior to the tensile tests. The electrolyte solution was a 1:1 mixture of sulfuric acid and phosphoric acid. The electro polishing was performed at room temperature at a voltage 8 10 V. Tensile tests were performed with an MTS machine at a cross head speed of $0.008 \mathrm{~mm} / \mathrm{s}$, equivalent to an initial strain rate of $1 \times 10^{-3} \mathrm{~s}^{-1}$. The hardness was measured by an LM 300AT micro hardness tester using a $2.9 \mathrm{~N}$ force for a loading time of $13 \mathrm{~s}$ by using a pyramidal shape diamond indenter. Scanning electron microscopy (SEM) was performed on an FEI Quanta 600 microscope operated at an acceleration voltage of $20 \mathrm{kV}$ at a working distance of $10 \mathrm{~mm}$. The optical microscopy (OM) and SEM specimens were cut from the tensile specimen away from the deformation zone. Samples were prepared following the standard mechanical polishing process, 


\section{Results}

\subsection{Microstructure and mechanical properties of as-quenched T91 steel}

Fig. 2 shows the schematic of phase constitution and morphological feature of the transformation products of water quenched T91 steel heat treated at $800 \sim 1200^{\circ} \mathrm{C}$ for $1 \mathrm{~h}$, which is detailed in the following section. The packet is defined as a group of martensite with the same habit plane that can be subdivided into blocks. Blocks are typically identified as a group of martensite with similar orientation or a combination of two variants with different orientations. The definition of various phases of transformation products are based mainly on their morphology or precipitates therein.

OM (Fig.3) and SEM (Fig.4) images were collected simultaneously to examine the microstructure of WQ T91 steel. The interpretation of these images is based on the different morphologies of these phases subjected to the etchant. For instance, ferrite phases typically have a clean blocky appearance in OM micrographs labeled as $\alpha_{\mathrm{p}}$. The "blocky" ferrite phase is easily etched away and thus appears "deeper" in the SEM images. Examples for this type of ferrite include $\alpha_{A}$ and $\alpha_{B}$. The fine martensites (martensite block) typically have lath morphologies in both OM and SEM micrographs in nearly all the WQ specimens. In what follows, we will discuss the evolution of microstructures of T91 heat treated at different temperatures (from low to high) followed by water quenching, examined by OM (Fig.3), SEM (Fig.4) and TEM (Fig.5) techniques.

The AA T91 steel shown in Fig.3a has typical tempered martensitic lath structure $\left(\alpha_{\mathrm{T}}^{\prime}\right)$ with minor second phases, including retained austenite or martensite (M/A constituent), and/or transformed carbides. The fully tempered T91 is mainly composed of ferrite phase with packet and block boundaries. Prior austenite grain boundaries (PAGBs) and packet boundaries are often 

AA specimen dominate the microstructures inside a packet as shown in the TEM micrograph in Fig.5a.

Water quenching of $\mathrm{T} 91$ from $800^{\circ} \mathrm{C}$ leads to fine microstructures as shown in Fig.3b. SEM studies (in Fig.4b) show that this fine structure is a mixture of grain boundary ferrite $\left(\alpha_{\mathrm{A}}\right)$, martensite $\left(\alpha_{M}^{\prime}\right)$ and ferrite $\left(\alpha_{P}\right)$. Some martensitic blocks within prior austenite grains were etched as shown in Fig.4b. A prior austenite grain in the 800WQ specimen is surrounded by adjacent $\alpha_{A}$ containing undissolved carbides (Fig.5b). The ferrite phase $\left(\alpha_{P}\right)$ and fine martensites are occasionally separated by a packet boundary highlighted by a red dotted line in Fig.5c.

The microstructures of the water quenched 900 and $1000^{\circ} \mathrm{C}$ specimens (900WQ and 1000WQ) have primarily martensite $\alpha_{M}^{\prime}$ and polygonal ferrite $\left(\alpha_{P}\right)$ shown typically as light clean grains in OM micrographs in Fig.3c-d. $\alpha_{\mathrm{A}}$ is absent in the 900WQ specimens (Fig.4c). A packet containing non-etched blocks is highlighted by a red dotted line in Fig.4c. PAGBs are also observed in the 900WQ specimen (as marked in Fig.4c). The TEM image shows a triple junction of prior austenite grains in the 900WQ T91 in Fig.5d. Retained $\gamma$ is identified as the thin layers between martensite laths with dark contrast in Fig.5d. The $\alpha_{\mathrm{P}}$ ferrite with martensite precipitates is also observed in the 900WQ specimen as shown in Fig.5e.

Significant coarsening of austenite grains occurs after heat treatment at $1100^{\circ} \mathrm{C}$ or higher prior to water quenching as shown in the 1100WQ and 1200WQ specimens in Fig.3e-f. Blocks are clearly observed in these two specimens. Except for packets around the grain boundaries, no packet boundaries are identified due to the randomly oriented blocks. Bainitic ferrite $\left(\alpha_{B}\right)$ within the prior austenite grains in the 1100WQ and 1200WQ specimens was preferentially etched away as shown in Fig.4d. Auto-tempered martensite $\left(\alpha_{\mathrm{AT}}^{\prime}\right)$ is frequently observed as shown in Fig.5f in the 1200WQ specimen. Carbides are trapped within the martensite laths.

The heat treatment temperature prior to water quenching can change the austenite grain size and consequent microstructure in water quenched T91. Fig.6a shows the overall martensite microstructure within a prior austenite grain in the 1000WQ specimen before the austenite grains coarsen. Single variant blocks are identified within a packet. Fig.6b shows the 1100WQ specimen, which has the transformed structure after coarsening of the austenite. The blocks are thicker and longer than those in the 1000WQ specimen. Also no packets can be identified due to the random arrangement of the blocks. 
Fig.7 shows the average grain size of the prior austenite grains in the WQ T91 steel according to the SEM images. The grain sizes are similar in the AA, 900WQ and 1000WQ specimens. For specimens heated to $1100^{\circ} \mathrm{C}$ or greater (1100WQ and 1200WQ), the average grain size increased by an order of magnitude from $\sim 13$ to $150 \mu \mathrm{m}$.

Carbides in auto-tempered martensite and bainitic ferrite were studied in detail in Fig.8 and Fig.9. The detection of carbides requires the tilting of TEM specimens to remove contrast from forest dislocations. Fig.8 shows typical microstructures within an auto-tempered martensite (1200WQ). Black needle-shape precipitates are identified in the specimen tilted to the near two beam (TB) condition in Fig.8a. The contrast was reversed in Fig.8b taken at weak beam dark field condition. High resolution TEM (HRTEM) images combined with its fast Fourier transform (FFT) confirm that the precipitates are primarily $\eta$-carbide (Fig.8c) and cementite (Fig.8d). The orientation relationship between $\eta$-carbide and the matrix follows $\eta-C[010] / / \alpha^{\prime}[011], \eta-C(001)$ $/ / \alpha^{\prime}(200)$, which is compatible with the orientation relationship proposed by Hirotsu and Nagakura [42]. The growth direction of $\eta$-carbide is close to $\eta-C[001] / / \alpha^{\prime}[200]$. The satellite diffraction spots in the FFT in Fig.8c stem from the modulation in $\eta$-carbide. The cementite has an orientation relationship $\theta[100] / / \alpha^{\prime}[011]$, and $\theta(002) / / \alpha^{\prime}(\overline{2} \overline{1} 1)$ with the matrix, which corresponds well to a classic Bagaryatskii relationship [43].

Martensite and carbides are observed within the bainitic ferrite matrix in Fig.9a in the 1200WQ specimen. Precipitates in bainitic ferrite align along nearly the same direction, in comparison to randomly oriented precipitates in auto-tempered martensite in the 1200WQ material. The HRTEM micrograph in Fig.9b reveals a substantial amount of strain contrast around the needle-shape precipitates, which were identified to be $\varepsilon$-carbide as evidenced by FFT analysis. The classic Jack orientation relationship between carbide and ferrite prevails [44], that is $\alpha[1 \overline{1} 1] / / \varepsilon-\mathrm{C}[1 \overline{2} 10], \alpha(011) / / \varepsilon-\mathrm{C}(000 \overline{2})$. The growth direction of $\varepsilon$-carbide is along the $\varepsilon^{-}$ $\mathrm{C}[10 \overline{1} 0]$, which is parallel to $\alpha[21 \overline{1}]$, consistent with early studies by Murphy et al[45].

Fig.10 provides a comparison of engineering and true stress-strain curves of various WQ T91 steel. In general, the WQ T91 steels show a combination of high strength and ductility. The yield strength $\left(\sigma_{0.2}\right)$ of $800 \mathrm{WQ}$ material is $970 \mathrm{MPa}, \sim 150 \mathrm{MPa}$ lower than those heat treated above $900^{\circ} \mathrm{C}$. The uniform elongation is $\sim 7 \%$ for all of the WQ T91 steel, which is insensitive to austenitizing temperature prior to water quenching. Table 4 summarizes the effect of 
austenitizing temperature on phase constituents (before and after water quenching), and mechanical properties.

\subsection{ECAE enabled TMT of T91 steel}

SEM micrographs of the TMT processed T91 steel (heat treated to $1000^{\circ} \mathrm{C}$ prior to quenching) are shown in Fig.11. Similar to the 900WQ T91 steel, the 1000WQ specimens shows a predominant martensite phase. Packets containing blocks are commonly observed near the PAGBs. Air cooling of T91 after normalization at $1000^{\circ} \mathrm{C}(1000 \mathrm{AC})$ can also result in a complex transformed structure, which includes $\alpha_{M}^{\prime}, \alpha_{\mathrm{AT}}^{\prime}$, and $\alpha_{\mathrm{P}}$. More block boundaries are observed presumably because of the auto-tempering process. Further tempering of $1000 \mathrm{WQ}$ T91 at $500^{\circ} \mathrm{C}$ promotes the formation of carbides at the PAGBs, as shown in Fig.11c. Block boundaries can also be observed. The extrusion of tempered T91 at $300^{\circ} \mathrm{C}(1000 \mathrm{WQ} / 500 \mathrm{C} 10 \mathrm{~h} / 1 \mathrm{~A} 300)$ leads to curved (distorted) PAGBs (Fig.11d). The prominent shearing of prior austenite grains is frequently observed in the ausformed T91 steel (via ECAE at $1000^{\circ} \mathrm{C}$ ), as shown in Fig.11e.

Fig.12 shows representative TEM micrographs of the TMT processed T91 steel. Compared to abundant martensite laths and blocks in the 1000WQ specimen (Fig.12a), the 1000WQ/500 10h specimen has a typical tempered martensite structure with large patches of ferrite (Fig.12b). Further ECAE processing of this tempered specimen (1000WQ/500 10h/1A300) leads to deformed martensite with a high density of dislocations (Fig.12c). Fragmented martensite laths containing numerous small grains are also observed as shown in Fig.12c. Ausforming of $\mathrm{T} 91$ at $1000^{\circ} \mathrm{C}(1000 \mathrm{ECAE})$ produces a textured martensite structure with much shorter laths (Fig.12d) than those in the 1000WQ specimen.

The thermal stability of T91 produced via different routes was probed by measuring the evolution of the Vickers hardness (at room temperature) after annealing at different temperatures up to $800^{\circ} \mathrm{C}$, as shown in Fig. 13. The hardness of the AA material remains the same throughout the annealing experiment. In comparison, the hardness of the $2 \mathrm{~B} 300$ specimen (two pass extrusion following route $\mathrm{B}$ at $300^{\circ} \mathrm{C}$ ) is nearly $60 \%$ greater up to $500^{\circ} \mathrm{C}$ and softened afterwards. The hardness of the 1000ECAE material is 2.3 times that of the AA T91mateirial up to $500^{\circ} \mathrm{C}$, followed by rapid softening at higher annealing temperatures.

Fig.14 illustrates the tempering response of 1000ECAE T91 at various temperatures. After tempering at $600^{\circ} \mathrm{C}$, tiny carbides precipitate at martensitic lath boundaries as shown in 
Fig.14a. Significant coarsening of carbides and the prominent loss of lath structures are evident for T91 steel tempered at $700^{\circ} \mathrm{C}$ as shown in Fig.14b. The remaining sparsely distributed tempered martensitic laths are coarsened dramatically with "blunted tips" (Fig.14c). The microstructure is fully recrystallized with an average grain size of $\sim 660 \mathrm{~nm}$. The martensite structure is rarely preserved after normalization at $800^{\circ} \mathrm{C}$, as shown in Fig. $14 \mathrm{~d}$.

The engineering and true stress-strain curves of TMT T91 steels are displayed in Fig.15. The yield strength of AA material is increased by a factor of $\sim 3$, from $\sim 482$ to $1600 \mathrm{MPa}$ after selected TMT processing. Direct quenched T91 steel exhibits a good combination of strength and ductility. TMT of T91 steels further enhances their mechanical strength with moderate loss of tensile ductility as shown in Fig.15b.

\section{Discussion}

\subsection{Microstructure evolution of TMT processed T91 steel}

\subsubsection{Microstructure of the water quenched T91 steels}

In the current study, $\delta$-ferrite was absent in the selected austenization range of $800 \sim 1200^{\circ} \mathrm{C}$ in $\mathrm{T} 91$ steel, consistent with earlier studies that show $\delta$-ferrite formed during normalization above $1250^{\circ} \mathrm{C}$ for 5 min or longer $[46,47]$. $\delta$-ferrite is detrimental to the creep strength of T91 [48]. Compared to T9 steel wherein more than $35 \% \delta$-ferrite is present at $1200^{\circ} \mathrm{C}$ or higher temperature [49], the modified T91 steel (with the addition of minor elements, like $\mathrm{Nb}$ and $\mathrm{V}$ ) shows a wider $\gamma$-phase region to avoid $\delta$-ferrite. Although there is no $\delta$-ferrite, a full martensite microstructure is not obtained in any of the current water quench specimens.

Martensitic transformation of the $\gamma$ phase was incomplete in water quenched specimens (preheated to 800,900 and $1000^{\circ} \mathrm{C}$ ), where a polygonal ferrite is observed within the prior austenite grains. The suppression of martensitic transformation could be related to the small austenite grain size $[50,51]$. This size dependent martensitic transformation is related to grain size induced strengthening of the austenite matrix [51]. Nucleation of martensite undergoes plastic accommodation due to a geometric strain in the martensite [52]. Fine austenite grains can strengthen the matrix and suppress the nucleation and growth of martensite, thus significantly lower the martensitic transformation temperature. A similar effect will be addressed in ausformed T91 steels described below. In the present study, martensite precipitates are frequently observed in the polygonal ferrites in specimens heated to $1000^{\circ} \mathrm{C}$, implying an 
insufficient driving force to complete the martensitic phase transformation. The longer martensite lath formed in the larger prior austenite grains in $\mathrm{T} 91$ heated above $1100^{\circ} \mathrm{C}$ follows the same principle. The large austenite grain size produces less plastic constraint on transformed martensite, thus the formation of larger martensite is encouraged.

Bainitic ferrite in the T91 steel quenched from 1100 and $1200^{\circ} \mathrm{C}$ is a phase commonly observed in some low carbon steels [30, 53, 54], but rarely reported in T91 steel. The larger grain size not only increases the martensitic transformation temperature but also favors the bainitic transformation. The direct impact of the increased martensitic transformation temperature is an auto-tempering effect of martensite. The possibility of bainitic transformation is supported by an early study of time-temperature-transformation (TTT) diagram of low carbon steels [30] or rapid quenching of binary alloys [31], where a bainitic transformation often occurs prior to martensitic transformation if the cooling rate is reduced. Bainitic ferrite is frequently observed within the prior austenite grains rather than at grain boundaries implying a higher local carbon concentration in the vicinity of grain boundaries, supported by the fact that some of the martensite and packets are formed around the boundaries as shown in Figs.3e,6a and 9a. The grain boundaries should have both mechanical (strengthening) and chemical (carbon sinks) effects on the martensitic transformation.

The morphology of transformation products of the water quenched T91 is another subject inviting discussion. As shown schematically in Fig.2, the $\gamma$-transformed microstructure is similar among 800WQ, 900WQ and 1000WQ specimens and typically contains a grain boundary packet of the martensite (a packet of martensite close to PAGBs) together with large polygonal or plate ferrite. Within the grain boundary packet, there are usually blocks similar to the previous observation by Morito et al. in low carbon steel [35]. The abundant large single variant blocks are separated from other blocks composed of smaller martensite regions. The martensite exists as a precipitate in polygonal ferrite or in between the large ferrite regions. The $\gamma$-transformed microstructure is different in 1100WQ and 1200WQ T91. Grain boundary packets are observed frequently, while within the grains, no clear packet boundaries are observed. The blocks within a packet distribute randomly similar to the previous observation in certain high carbon $\mathrm{Fe}-\mathrm{C}$ alloys [35].

\subsubsection{Microstructure after TMT processing}


The ECAE enabled TMT of T91 steel (1000ECAE) is an ausforming process. Ausforming can significantly influence the variant selection of the martensite $[55,56]$. This phenomena may be qualitatively described by [57]:

$U=\tau \gamma_{0}+\sigma \varepsilon_{0}$

where $U$ is interaction energy, $\tau$ is the shear stress resolved on the habit plane of a variant, $\sigma$ is the stress resolved normal to the habit plane, and $\gamma_{0}$ and $\varepsilon_{0}$ are the shear and normal component of the transformation strain of the variant, respectively. A greater interaction energy can enhance the formation of that variant. The normal stress $\sigma$ can facilitate or depress the variant while shear stress often stimulates the formation of a variant. As shear deformation dominates during ECAE, the variants with habit planes close or parallel to the shear plane may form first. The martensite laths formed later are either thinner or shorter due to limited available free space and stress arising from the prior formed thicker martensite laths as shown in early studies $[55,56]$. Detailed review of variant selection is given by Kundu recently [58]. Gong et al. suggested that a bainite transformation may be accelerated by ausforming [59]. As mentioned previously, this argument could also be applied to the size effect on martensitic transformation, that is, grain refinement (by ECAE) leads to stronger matrix and significantly lowers the martensitic transformation temperature.

After annealing of $1000 \mathrm{WQ}$ T91 steel at $500^{\circ} \mathrm{C}$ for $10 \mathrm{~h}$, the material becomes a moderately tempered martensite because at this annealing temperature, the microstructure evolution is limited to the diffusion of carbon [28]. Thus, more carbides are observed at the block boundaries than in the WQ specimens. ECAE of this tempered martensite structure (1000WQ/500 10h/1A300) does not lead to refinement of martensite laths, but significantly increases the dislocation density. Fragmented martensite laths are observed as well. Small grains are occasionally observed within the martensitic lath with a growth direction perpendicular to the martensite lath.

The heat treatment of 1000ECAE T91 steel is similar to the tempering of martensite [60], which is often controlled by the diffusion of carbon atoms and precipitation of carbides. Carbon is the primary element that can significantly diffuse in $\mathrm{T} 91$ steel below $500^{\circ} \mathrm{C}$ [28]. After tempering at $600^{\circ} \mathrm{C}$, the carbides precipitate along the lath boundaries. In the meantime, the residual austenite decomposes to form carbides. At $700^{\circ} \mathrm{C}$, the carbides along the lath interphase spheroidize and coarsen significantly. Thinner martensites with the same habit plane and slight 
misorientation, produced by water quenching, merge together to form the tempered martensite structure with a typical thickness of $500 \mathrm{~nm}$. After tempering at $800^{\circ} \mathrm{C}$ for $1 \mathrm{~h}$, martensite decomposes followed by significant recrystallization, and thus leads to the formation of equiaxed ferrite with carbides.

\subsection{Mechanical properties of TMT processed T91 steel}

\subsubsection{Strengthening mechanisms}

We will use two sets of strengthening mechanisms (SM1 and SM2) to interpret strengthening in T91 steels.

Frist, for steels with primarily martensite and bainite, the yield strength $\sigma_{\mathrm{y}}$ can be estimated by (strengthening mechanism one, SM1) [61]:

$\sigma_{y}=\sigma_{F e}+\sigma_{s}+\sigma_{P}+K_{L}(\bar{L})^{-1}+K_{D} \rho_{D}{ }^{1 / 2}$

where $\sigma_{\mathrm{Fe}}$ is the strength of annealed pure $\mathrm{Fe}, \sim 100 \mathrm{MPa}[62], \sigma_{\mathrm{s}}$ is the solid solution strengthening, $\sigma_{\mathrm{P}}$ is the precipitation hardening, $\mathrm{K}_{\mathrm{L}}$ is the coefficient due to lath size with a value of $115 \mathrm{MPa} \cdot \mu \mathrm{m}[61], \bar{L}$ is the average lath size (with units of $\mu \mathrm{m}$ ) and is $\sim 0.2 \mu \mathrm{m}$ for martensite and $\sim 0.5 \mu \mathrm{m}, \mathrm{K}_{\mathrm{D}}$ is the coefficient due to dislocation strengthening with a value of $7.34 \times 10^{-}$ ${ }^{6} \mathrm{MPa} \cdot \mathrm{m}[61]$, and $\rho_{\mathrm{D}}$ is the dislocation density.

The solid solution hardening (in unit of $\mathrm{MPa}$ ) $\sigma_{\mathrm{s}}$ can be estimated by [61],

$$
\sigma_{s}=\sum \sigma_{s s}+\sum \sigma_{i}=1723 \sqrt{[C]}+5.8[C r]+18[M o]+105[S i]+45[M n]+37[N i]+4.8[V]
$$

where all the elements $[\mathrm{Z}]$ are in weight percent.

The precipitation hardening is estimated by using the Ashby-Orowan relationship [63],

$$
\sigma_{p}=\left(0.538 G b f^{1 / 2} / X\right) \ln (X / 2 b)
$$

where $\mathrm{G}$ is the shear modulus of Fe, $\sim 82 \mathrm{GPa}, \mathrm{b}$ is the Burgers vector, $2.49 \times 10^{-10} \mathrm{~m}$ for the present alloy, $\mathrm{f}$ is the volume fraction of particles, and $\mathrm{X}$ is the diameter of the particles.

Next, the combinational strengthening from various mechanisms in steel can also be estimated by another equation given by Krauss (strengthening mechanism two, SM2)[33],

$$
\sigma_{y}=\sigma_{F e}+\sigma_{s s}+k_{D} D^{-1 / 2}+k_{d} d^{-1 / 2}+\alpha G b \rho^{1 / 2}
$$

where $D$ is the packet size, $d$ is the lath width, $\mathrm{k}_{\mathrm{D}}$ and $\mathrm{k}_{\mathrm{d}}$ are Hall-Petch coefficients for packets and laths, $\alpha$ is 0.4 for BCC metal [62], $\rho$ is the dislocation density in martensitic lath, and the other terms have the same meaning as defined previously. The Hall-Petch strengthening 
coefficient is $\sim 100 \mathrm{MPa} \cdot \mu \mathrm{m}^{1 / 2}$ for prior austenite grains in low alloy carbon steels [64], because the packet size shows a linear dependence on the prior austenite grain size with a coefficient of $\sim 1 / 3[65]$. A $\mathrm{k}_{\mathrm{D}}$ value around $170 \mathrm{MPa} \cdot \mu \mathrm{m}^{1 / 2}$ is achieved. The $\mathrm{k}_{\mathrm{d}}$ value is not well documented. However, the importance of block size is realized by Morito et al [65]. Here we use the block size $\mathrm{d}$ instead of lath width, which is around $\sim 2.5 \mu \mathrm{m}$. Thus the previously reported $\mathrm{k}_{\mathrm{d}}$ value of $\sim$ $700 \mathrm{MPa} \cdot \mu \mathrm{m}^{1 / 2}$ is used for block boundary in low carbon steels [65].

Morito et al [66] also studied the influence of carbon concentration on the dislocation density in martensite lath. A linear relationship is extracted by Hutchinson et al. as follows[67], $\rho=\rho_{0}+K(\% C)=(0.7+3.5 w t . \% C) \times 10^{15}$

where $\rho_{\mathrm{o}}$ is the dislocation density in martensitic pure iron, $\mathrm{K}$ is the increase in dislocation density caused by carbon (in wt.\%). The values of $\mathrm{K}$ and $\rho_{\mathrm{o}}$ in equation (6) can be obtained from the same reference.

The solid solution strengthening induced by $\mathrm{C}$ is well addressed in martensitic steels [33, 68]. However, the strengthening induced by $\mathrm{N}$ is limited to austenite steels [69-71]. In martensite, the role of $\mathrm{N}$ in strengthening is not well understood. Here, we assume that the efficiency of $\mathrm{N}$ on strengthening of martensite is nearly equivalent to $\mathrm{C}$.

As summarized in Table 5, the 3 major strengthening terms in SM1 are $\sigma_{\mathrm{i}}(610 \mathrm{MPa}), \sigma_{\mathrm{H}-\mathrm{P}}$ $(560 \mathrm{MPa})$, and $\sigma_{\text {disl. }}(250 \mathrm{MPa})$. In comparison, the SM2 method has two major strengthening contributors, $\sigma_{\mathrm{H}-\mathrm{P}}(440 \mathrm{MPa})$ and $\sigma_{\text {disl. }}(250 \mathrm{MPa})$. Both mechanisms have similar values of $\sigma_{\mathrm{Fe}}$ (100MPa) and $\sigma_{\mathrm{ss}}(130 \mathrm{MPa})$. In SM1, the strengthening arising from $\mathrm{C}$ and $\mathrm{N}$ appears substantial, because they can both distort the lattice and block dislocations through Cottrell atmospheres [72].

Comparisons with experimental results show that the SM1 approach overestimates the yield strength by $\sim 440 \mathrm{MPa}$. The influence of $\mathrm{C}$ or martensite lath size on strengthening may have been overestimated. For example, in the term that accounts for carbon induced strengthening in eq. (3), the coefficient is calculated by considering the thickness of the martensitic lath, $\sim 0.25 \mu \mathrm{m}$ [33]. While in the eq. (2), the size of lath boundaries is considered again in the size effect term.

Meanwhile, the SM2 method underestimates the yield strength by $280 \mathrm{MPa}$. This could be due to the lack of several coefficients, such as $\mathrm{k}_{\mathrm{D}}$ or $\mathrm{k}_{\mathrm{d}}$ for the T91 steel. The use of the coefficient for low carbon steel may not be well suited for the current study. Also the influence of interstitials on strengthening was not considered and may lead to underestimate of the yield 
strength. Additional discrepancy may arise from the fact that a full martensite structure is not achieved. For instance, a small amount of bainitic ferrite is observed in the 1100WQ specimen. The linear superposition rule adopted in both methods may also require revisions as the strengthening contributions from various terms may be convoluted to some extent.

A dislocation based method derived from strain hardening could be another approach to interpret strengthening [73]. In this case, the dislocation mean free path is a key link between the dislocation-barrier interaction and strain hardening [74]. The different strengthening terms in eqs.(2) and (5) arise from various barriers for the movement of dislocations and thus can be affected by the mean free path of dislocations. Although different attempts have been made[75, 76], the determination of dislocation mean free path for various barriers remains an open question.

Also it is worth mentioning that the softening in the 1000ECAE and 2B300 specimens after annealing, though occurring both at $600^{\circ} \mathrm{C}$ (as shown in Fig.13), may have different underlying mechanisms. As the 1000ECAE specimens have primarily martensite, its softening after tempering is due to the decomposition of martensite. In contrast, the 2B300 specimen has mostly ferrite, and the softening after annealing is primarily due to grain coarsening.

\subsubsection{The influence of TMT on work hardening capability and ductility of T91 steels}

The ductility is characterized through a key parameter, known as uniform elongation. It is determined by the Considère criterion [77],

$$
\left(\frac{\partial \sigma}{\partial \varepsilon}\right)_{\dot{\varepsilon}}=\sigma
$$

where $\sigma$ and $\varepsilon$ are true stress and true strain, $\dot{\varepsilon}$ is strain rate, and $\partial \sigma / \partial \varepsilon$ is the work hardening rate. When a material is subjected to a strain at the onset of necking, its work hardening cannot sustain the geometrical weakening of the deformed region[78, 79]. The strain achieved up to necking is considered as true uniform elongation.

Fig.16 compares the true stress-strain and work hardening rate of several representative cases of the TMT processed T91. The AA specimen has a high work hardening rate and large uniform elongation as the large grains can accommodate a rapid increase of the density of mobile dislocations during deformation. In contrast, the 1000WQ specimen has less work hardening capability and uniform strain as its smaller martensite laths already contain a high density of dislocations. 
Finally we examine the yield strength-uniform elongation paradox in T91 steels. A majority of metallic materials, such as those processed by cold working, follow the general syndrome: the strengthening of a material accompanied by a reduction in ductility[24].

As shown in Fig.17, the TMT processes enable us to tailor the mechanical properties of T91 steel over a broad range. Three distinct groups are highlighted on this plot. First, the light blue band outlines T91 steel with primarily ferrite phases. These steels were processed via ECAE at low-to-intermediate temperatures (room temperature to $700^{\circ} \mathrm{C}$ ). The higher strength of ferritic T91 steels originates mostly from grain refinement. The highest strength achieved in ferritic T91 steel in this study is $1000 \mathrm{MPa}$ with a mere $2 \%$ uniform elongation. In the second category (dominated by martensite shown as red band in Fig.17), TMTs via austenitizing at $900^{\circ} \mathrm{C}$ or greater (followed by water quenching) and ECAE at $1000^{\circ} \mathrm{C}$ induce primarily martensite. The yield strength of 1000WQ/500 10h/1A300 T91 exceeds $1600 \mathrm{MPa}$ with, however, only 1.5\% uniform elongation. Heat-treatment of the ECAE specimens leads to an improvement of uniform elongation, to $\sim 4 \%$, with a yield strength of $1400 \mathrm{MPa}$. The third category includes T91 steels processed by water quenching at $800^{\circ} \mathrm{C}$ or water quenching at $900 \sim 1200^{\circ} \mathrm{C}$ followed by a $600^{\circ} \mathrm{C}$ tempering procedure as shown in the purple band. T91 processed by this route is composed of both ferrite and martensite. The formation of ferrite reduces the yield strength by $\sim 150 \mathrm{MPa}$.

It is noteworthy that when the austenitizing process is performed above $900^{\circ} \mathrm{C}$, water quenching leads to the production of F/M T91 steel composed primarily of martensite. The asquenched martensite results in a high yield strength, $1200 \mathrm{MPa}$, as well as a reasonable uniform elongation, $\sim 6-8 \%$ as shown by the yellow triangles. The retention of good ductility may be related to the low $\mathrm{C}$ concentration in T91 steel as well as auto-tempering of martensite during the cooling process. The accomplishment of high strength with good ductility via such a simple water quenching process is a very encouraging observation.

While the strength and ductility of martensitic T91 (red band) and ferritic T91 (light blue band) may still follow the paradoxical relationship, ductile martensite can bring the coordinates of the strength and ductility to a greater level beyond the ferrites. The F/M T91 (in the purple band) bridges the mechanical behavior between the two distinct groups (red and light blue band). This TMT roadmap thus permits the tailoring of T91 steels with various combinations of strength and ductility for different industrial and nuclear applications. 


\section{Summary}

The microstructure and mechanical properties of T91 steels subjected to various TMT processes were systematically investigated. The major findings are summarized as follows:

(1) Ausforming or austenitizing of T91 steels at $900^{\circ} \mathrm{C}$ or greater produces primarily martensite. These transformed martensites coupled with auto-tempering leads to materials with good ductility. Furthermore, bainitic ferrite is formed during the transformation.

(2) Transition carbides ( $\varepsilon$ - and $\eta$-carbides) are, probably for the first time, observed in water quenched T91 steel. Both orientation relationships of these carbides follow the classical orientation relationships.

(3) The strengthening mechanisms of thus processed T91 mainly involve the Hall-Petch type of strengthening, dislocation strengthening, and solid solution strengthening.

(4) A roadmap for tailoring the strength and ductility of T91 steel via TMT has been developed.

(5) Ductile martensite possesses much greater strength than fine grained ferrites.

\section{Acknowledgements}

We acknowledge financial support by NSF-DMR-Metallic Materials and Nanostructures Program under grant no. 1304101. M. Song and C. Sun were supported by DOE-NEUP under contract no. DE-AC07-05ID14517-00088120. Z. Fan is supported by NSF-CMMI under grant No. 1161978. The technical assistance on ECAE processing from Mr. Robert Barber is greatly appreciated. We also acknowledge the microscopy facilities at the Microscopy and Imaging Center (MIC) of Texas A\&M University. 


\section{References}

[1] S.J. Zinkle, G. Was. Materials challenges in nuclear energy, Acta Mater. 61 (2013) 735 758.

[2] F. Garner, M. Toloczko, B. Sencer. Comparison of swelling and irradiation creep behavior of fcc-austenitic and bcc-ferritic/martensitic alloys at high neutron exposure, J. Nucl. Mater. 276 (2000) 123-142.

[3] R. Klueh, A. Nelson. Ferritic/martensitic steels for next-generation reactors, J. Nucl. Mater. 371 (2007) 37-52.

[4] K. Murty, I. Charit. Structural materials for Gen-IV nuclear reactors: Challenges and opportunities, J. Nucl. Mater. 383 (2008) 189-195.

[5] M.J. Cohn, J.F. Henry, D. Nass. Fabrication, construction, and operation problems for grade 91 fossil power components, J. Press. Vess. Technol 127 (2005) 197-203.

[6] R. Swindeman, M. Santella, P. Maziasz, B. Roberts, K. Coleman. Issues in replacing CrMo steels and stainless steels with 9Cr-1Mo-V steel, Int.J .Pres. Ves. Pip. 81 (2004) 507-512.

[7] F. Abe, M. Taneike, K. Sawada. Alloy design of creep resistant $9 \mathrm{Cr}$ steel using a dispersion of nano-sized carbonitrides, Int.J .Pres. Ves. Pip. 84 (2007) 3-12.

[8] S. Ukai, M. Fujiwara. Perspective of ODS alloys application in nuclear environments, J. Nucl. Mater. 307 (2002) 749-757.

[9] R. Klueh. Elevated temperature ferritic and martensitic steels and their application to future nuclear reactors, Int. Mater.Rev. 50 (2005) 287-310.

[10] R.Z. Valiev, R. Islamgaliev, I. Alexandrov. Bulk nanostructured materials from severe plastic deformation, Pergamon, 2000.

[11] R. Valiev. Nanostructuring of metals by severe plastic deformation for advanced properties, Nat Mater 3 (2004) 511-516.

[12] T.G. Langdon, M. Furukawa, M. Nemoto, Z. Horita. Using equal-channel angular pressing for refining grain size, Jom 52 (2000) 30-33.

[13] D.C. Foley, K.T. Hartwig, S.A. Maloy, P. Hosemann, X. Zhang. Grain refinement of T91 alloy by equal channel angular pressing, J. Nucl. Mater. 389 (2009) 221-224.

[14] M. Song, R. Zhu, D. Foley, C. Sun, Y. Chen, K. Hartwig, X. Zhang. Enhancement of strength and ductility in ultrafine-grained T91 steel through thermomechanical treatments, J. Mater. Sci. 48 (2013) 7360-7373.

[15] Z. Fan, T. Hao, S. Zhao, G. Luo, C. Liu, Q. Fang. The microstructure and mechanical properties of T91 steel processed by ECAP at room temperature, J. Nucl. Mater. 434 (2013) 417 421.

[16] C. Sun, Y. Yang, Y. Liu, K. Hartwig, H. Wang, S. Maloy, T. Allen, X. Zhang. Thermal stability of ultrafine grained Fe-Cr-Ni alloy, Mater. Sci. Eng. A 542 (2012) 64-70.

[17] C. Sun, J. Ma, Y. Yang, K. Hartwig, S. Maloy, H. Wang, X. Zhang. Temperature and grain size dependent plastic instability and strain rate sensitivity of ultrafine grained austenitic Fe-14Cr-16Ni alloy, Mater. Sci. Eng. A (2014).

[18] C. Sun, D. Brown, B. Clausen, D. Foley, K. Yu, Y. Chen, S. Maloy, K. Hartwig, H. Wang, X. Zhang. < i In situ $</ i>$ neutron diffraction study on temperature dependent deformation mechanisms of ultrafine grained austenitic $\mathrm{Fe}-14 \mathrm{Cr}-16 \mathrm{Ni}$ alloy, Int. J. Plast. 53 (2014) 125-134.

[19] M. Song, C. Sun, J. Jang, C. Han, T. Kim, K. Hartwig, X. Zhang. Microstructure Refinement and Strengthening Mechanisms of a 12Cr ODS Steel Processed by Equal Channel Angular Extrusion, J. Alloy. Compd 577 (2013) 247-256. 

properties of ODS Fe14Cr model alloy processed by ECAP, Mater. Sci.Technol. (2014). [21] C. Sun, K.Y. Yu, J.H. Lee, Y. Liu, H. Wang, L. Shao, S.A. Maloy, K.T. Hartwig, X. Zhang. Enhanced radiation tolerance of ultrafine grained $\mathrm{Fe}-\mathrm{Cr}-\mathrm{Ni}$ alloy, J. Nucl. Mater. 420 (2012) 235-240.

[22] M. Song, Y. Wu, D. Chen, X. Wang, C. Sun, K. Yu, Y. Chen, L. Shao, Y. Yang, K. Hartwig, X. Zhang. Response of equal channel angular extrusion processed ultrafine-grained T91 steel subjected to high temperature heavy ion irradiation, Acta Mater. 74 (2014) 285-295. [23] C. Sun, S. Zheng, C. Wei, Y. Wu, L. Shao, Y. Yang, K. Hartwig, S. Maloy, S. Zinkle, T. Allen. Superior radiation-resistant nanoengineered austenitic 304L stainless steel for applications in extreme radiation environments, Sci. Rep 5 (2015).

[24] R. Valiev, I. Alexandrov, Y. Zhu, T. Lowe. Paradox of Strength and Ductility in Metals Processed Bysevere Plastic Deformation, JMR 17 (2002) 5-8.

[25] K.-T. Park, Y.-S. Kim, J.G. Lee, D.H. Shin. Thermal stability and mechanical properties of ultrafine grained low carbon steel, Mater. Sci. Eng. A 293 (2000) 165-172.

[26] M. Eddahbi, M. Monge, T. Leguey, P. Fernández, R. Pareja. Texture and mechanical properties of EUROFER 97 steel processed by ECAP, Mater. Sci. Eng. A 528 (2011) 5927-5934. [27] R. Zhu, S. Li, M. Song, I. Karaman, R. Arroyave. Phase constitution effect on the ductility of low alloy multiphase transformation induced plasticity steels, Mater. Sci. Eng. A 569 (2013) 137-143.

[28] W.B. Jones, C. Hills, D. Polonis. Microstructural evolution of modified 9Cr-1Mo steel, Metall. Trans. A 22 (1991) 1049-1058.

[29] F. Abe. Precipitate design for creep strengthening of $9 \% \mathrm{Cr}$ tempered martensitic steel for ultra-supercritical power plants, Sci. Technol. Adv. Mater. 9 (2008) 013002.

[30] G. Krauss, S.W. Thompson. Ferritic microstructures in continuously cooled low-and ultralow-carbon steels, ISIJ Int. 35 (1995) 937-945.

[31] E. Wilson. $\gamma \rightarrow \alpha$ transformation in Fe, Fe-Ni, and Fe-Cr alloys, Metal Sci. 18 (1984) 471-484.

[32] G. Krauss, A. Marder. The morphology of martensite in iron alloys, Metall. Trans. 2 (1971) 2343-2357.

[33] G. Krauss. Martensite in steel: strength and structure, Mater. Sci. Eng. A 273 (1999) 40-

57.

[34] T. Maki, K. Tsuzaki, I. Tamura. The morphology of microstructure composed of lath martensites in steels, Trans. Iron Steel Inst.Jap 20 (1980) 207-214.

[35] S. Morito, H. Tanaka, R. Konishi, T. Furuhara, T. Maki. The morphology and crystallography of lath martensite in Fe-C alloys, Acta Mater. 51 (2003) 1789-1799.

[36] S. Morito, X. Huang, T. Furuhara, T. Maki, N. Hansen. The morphology and crystallography of lath martensite in alloy steels, Acta Mater. 54 (2006) 5323-5331.

[37] A. Lambert-Perlade, A.-F. Gourgues, A. Pineau. Austenite to bainite phase transformation in the heat-affected zone of a high strength low alloy steel, Acta Mater. 52 (2004) 2337-2348.

[38] H. Flower, T. Lindley. Electron backscattering diffraction study of acicular ferrite, bainite, and martensite steel microstructures, Mater. Sci.Technol. 16 (2000) 26-40.

[39] T. Furuhara, H. Kawata, S. Morito, T. Maki. Crystallography of upper bainite in Fe-NiC alloys, Mater. Sci. Eng. A 431 (2006) 228-236. 

Hosemann, M. Toloczko, S. Maloy. SANS and TEM of ferritic-martensitic steel T91 irradiated in FFTF up to 184 dpa at $413^{\circ} \mathrm{C}$, J. Nucl. Mater. 440 (2013) 91-97.

[41] Q. Gao, Y. Liu, X. Di, L. Yu, Z. Yan. Martensite transformation in the modified high Cr ferritic heat-resistant steel during continuous cooling, J. Mater. Res. 27 (2012) 2779.

[42] Y. Hirotsu, S. Nagakura. Crystal structure and morphology of the carbide precipitated from martensitic high carbon steel during the first stage of tempering, Acta Metall. 20 (1972) 645-655.

[43] M. Wells. An electron transmission study of the tempering of martensite in an Fe-Ni-C alloy, Acta Metall. 12 (1964) 389-399.

[44] K. Jack. Structural transformations in the tempering of high-carbon martensitic steels, Iron Steel Inst. 169 (1951) 26.

[45] S. Murphy, A. Whiteman. The precipitation of epsilon-carbide in twinned martensite, Metall. Trans. 1 (1970) 843-848.

[46] A. Kumar, K. Laha, T. Jayakumar, K.B.S. Rao, B. Raj. Comprehensive microstructural characterization in modified $9 \mathrm{Cr}-1 \mathrm{Mo}$ ferritic steel by ultrasonic measurements, Metall. Mater. Trans. A 33 (2002) 1617-1626.

[47] R. Kishore, R. Singh, T. Sinha, B. Kashyap. The morphology and ageing behaviour of $\delta$ ferrite in a modified 9Cr-1Mo steel, J. Nucl. Mater. 195 (1992) 198-204.

[48] S. Kobayashi, K. Sawada, T. Hara, H. Kushima, K. Kimura. The formation and dissolution of residual $\delta$ ferrite in ASME Grade 91 steel plates, Mater. Sci. Eng. A 592 (2014) 241-248.

[49] F. Pickering, A. Vassiliou. Effect of austenitizing temperature on constitution, transformation, and tempering of 9Cr-1Mo steel, Metal. Technol. 7 (1980) 409-413.

[50] M. Umemoto, W. Owen. Effects of austenitizing temperature and austenite grain size on the formation of athermal martensite in an iron-nickel and an iron-nickel-carbon alloy, Metall.Trans. 5 (1974) 2041-2046.

[51] P. Brofman, G. Ansell. On the effect of fine grain size on the M s temperature in Fe27Ni-0.025 C alloys, Metall. Mater. Trans. A 14 (1983) 1929-1931.

[52] S. Kajiwara. Roles of dislocations and grain boundaries in martensite nucleation, Metall. Mater. Trans. A 17 (1986) 1693-1702.

[53] Y. Ohmori, H. Ohtani, T. Kunitake. BAINITE IN LOW-CARBON LOW-ALLOY HIGH-STRENGTH STEELS, Trans. Iron Steel Inst. Jap. 11 (1971) 250-259.

[54] P. Cizek, B. Wynne, C. Davies, B. Muddle, P. Hodgson. Effect of composition and austenite deformation on the transformation characteristics of low-carbon and ultralow-carbon microalloyed steels, Metall. Mater. Trans. A 33 (2002) 1331-1349.

[55] G. Miyamoto, N. Iwata, N. Takayama, T. Furuhara. Quantitative analysis of variant selection in ausformed lath martensite, Acta Mater. 60 (2012) 1139-1148.

[56] T. Chiba, G. Miyamoto, T. Furuhara. Variant selection of lenticular martensite by ausforming, Scripta Mater. (2012).

[57] J. Patel, M. Cohen. Criterion for the action of applied stress in the martensitic transformation, Acta Metall. 1 (1953) 531-538.

[58] S. Kundu. Outstanding issues in crystallographic variant selection in displacive transformations, Mater. Sci.Technol. 30 (2014) 867-870.

[59] W. Gong, Y. Tomota, M. Koo, Y. Adachi. Effect of ausforming on nanobainite steel, Scripta Mater. 63 (2010) 819-822. 
[60] G. Speich, W. Leslie. Tempering of steel, Metall. Trans. 3 (1972) 1043-1054.

[61] H. Bhadeshia, R. Honeycombe. Steels: Microstructure and Properties, ButterworthHeinemann, 2011.

[62] B.Q. Han, F.A. Mohamed, E.J. Lavernia. Mechanical properties of iron processed by severe plastic deformation, Metall. Mater. Trans. A 34 (2003) 71-83.

[63] T. Gladman. Precipitation hardening in metals, Mater. Sci. Technol. 15 (1999) 30-36.

[64] R. Grange. Strengthening steel by austenite grain refinement, ASM Trans Quart 59 (1966) 26-48.

[65] S. Morito, H. Yoshida, T. Maki, X. Huang. Effect of block size on the strength of lath martensite in low carbon steels, Mater. Sci. Eng. A 438 (2006) 237-240.

[66] S. Morito, J. Nishikawa, T. Maki. Dislocation density within lath martensite in Fe-C and Fe-Ni alloys, ISIJ Int. 43 (2003) 1475-1477.

[67] B. Hutchinson, J. Hagström, O. Karlsson, D. Lindell, M. Tornberg, F. Lindberg, M. Thuvander. Microstructures and hardness of as-quenched martensites $(0.1-0.5 \% \mathrm{C})$, Acta Mater. 59 (2011) 5845-5858.

[68] M. Cohen. Strengthening of steel, Trans. Metall.Soc.AIME (1962).

[69] J. Simmons. Overview: high-nitrogen alloying of stainless steels, Mater. Sci. Eng. A 207 (1996) 159-169.

[70] V.G. Gavriljuk, H. Berns. High nitrogen steels: structure, properties, manufacture, applications, Springer, 1999.

[71] J. Rawers, M. Grujicic. Effects of metal composition and temperature on the yield strength of nitrogen strengthened stainless steels, Mater. Sci. Eng. A 207 (1996) 188-194. [72] A.H. Cottrell, B. Bilby. Dislocation theory of yielding and strain ageing of iron, Proc. Phys.Soc.Sec. A 62 (1949) 49.

[73] H. Mecking, U. Kocks. Kinetics of flow and strain-hardening, Acta Metall. 29 (1981) 1865-1875.

[74] B. Devincre, T. Hoc, L. Kubin. Dislocation mean free paths and strain hardening of crystals, Science 320 (2008) 1745-1748.

[75] F. Roters, D. Raabe, G. Gottstein. Work hardening in heterogeneous alloys-a microstructural approach based on three internal state variables, Acta Mater. 48 (2000) 41814189.

[76] A.W. Thompson, M.I. Baskes, W.F. Flanagan. The dependence of polycrystal work hardening on grain size, Acta Metall. 21 (1973) 1017-1028.

[77] M.A. Meyers, K.K. Chawla. Mechanical behavior of materials, Cambridge University Press Cambridge, 2009.

[78] Y. Wang, E. Ma. Three strategies to achieve uniform tensile deformation in a nanostructured metal, Acta Mater. 52 (2004) 1699-1709.

[79] J. Gil Sevillano, P. Van Houtte, E. Aernoudt. Large strain work hardening and textures, Prog. Mater Sci. 25 (1980) 69-134. 


\section{Figures}

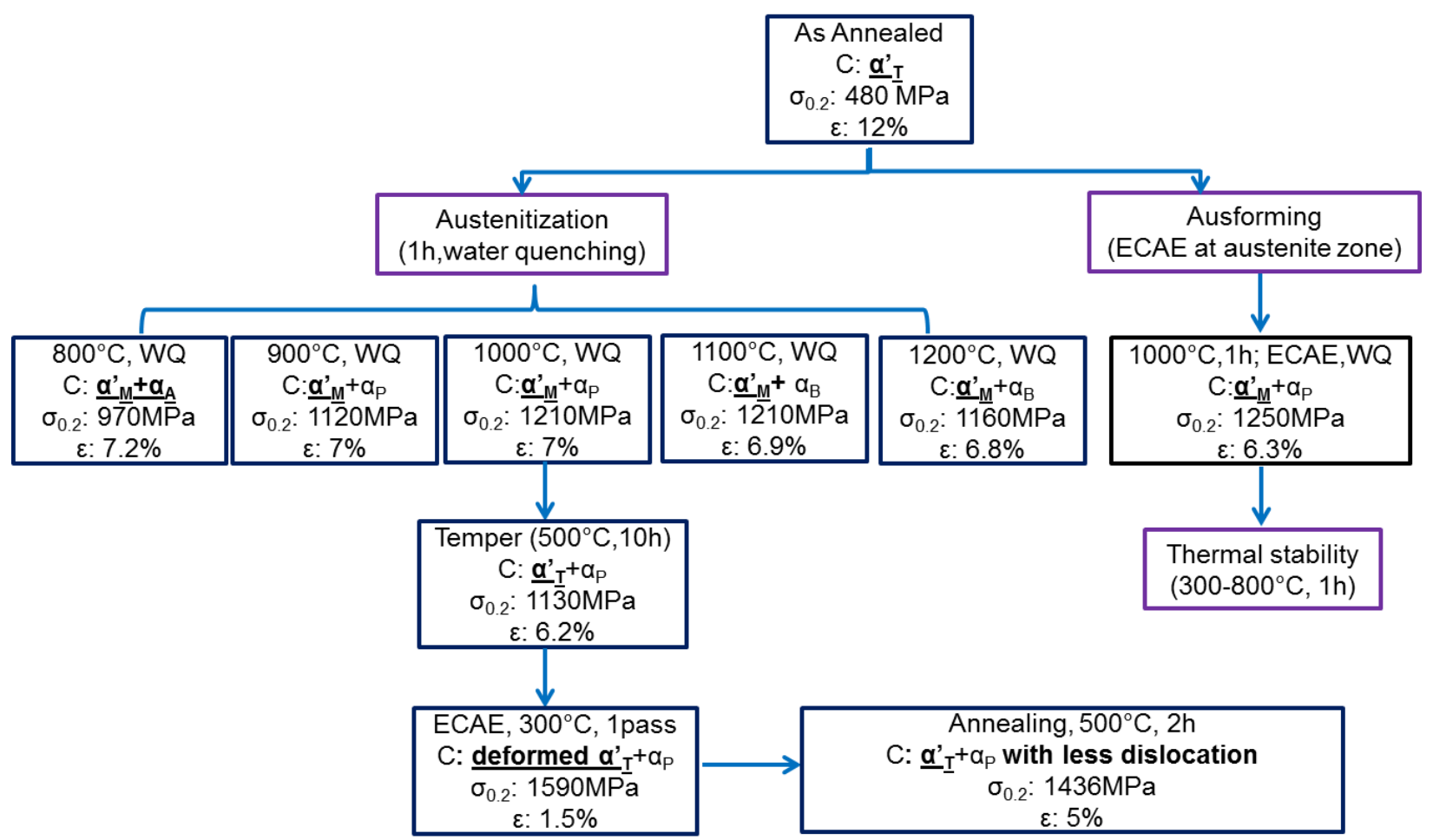

Fig.1. Flow chart of thermo-mechanical processing of T91 steel with microstructure features and mechanical performance after each treatment. Notation: $\mathrm{C}$ - major phase constitutions, $\sigma_{0.2}$ - yield strength, and $\varepsilon$ - uniform elongation. Note among multiple phases, the major phases are highlighted in bold fonts. 


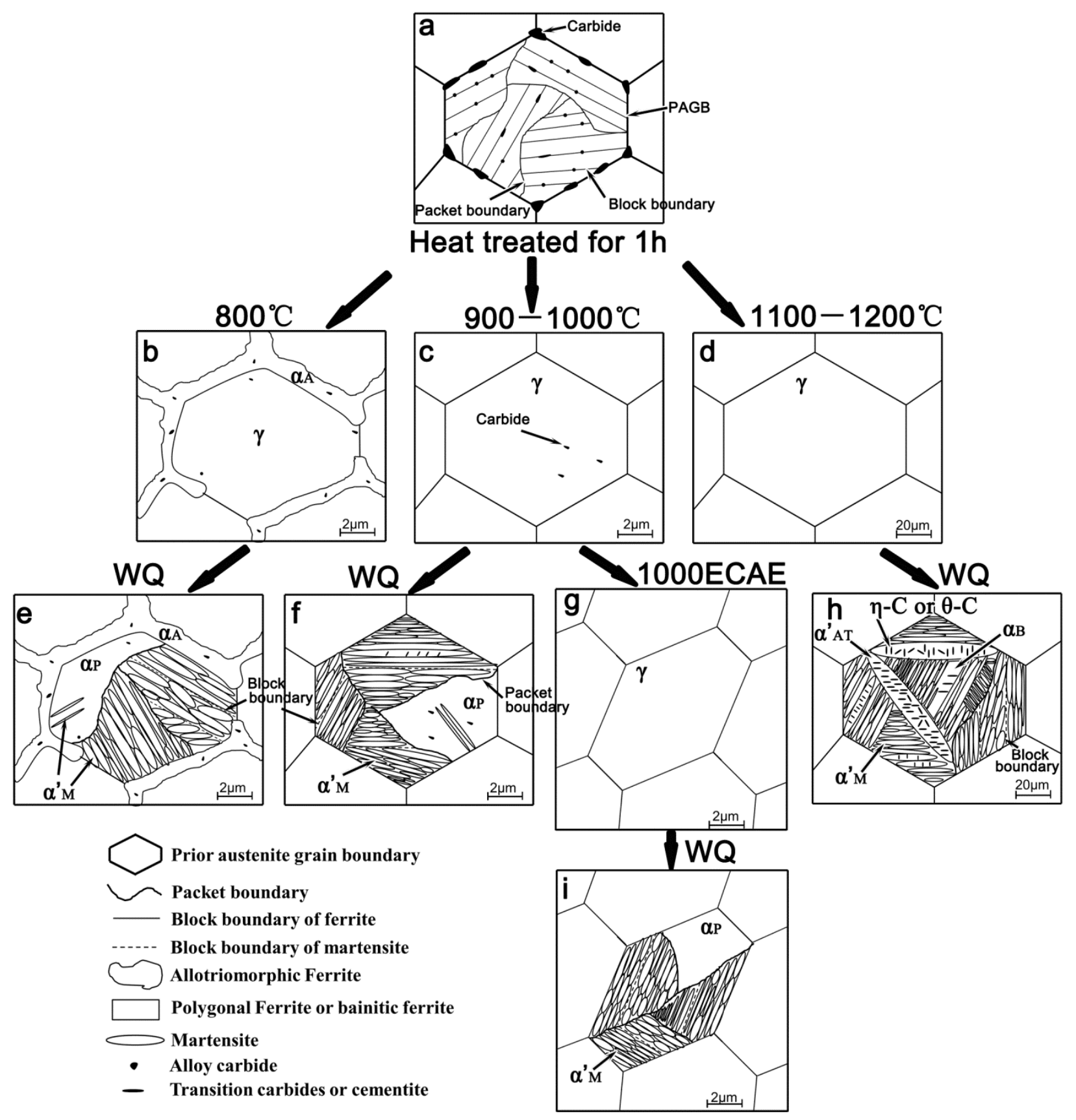

Fig.2 Schematic illustrations showing morphology of transformation products of T91 steel heating up to different austenization temperatures $\left(800 \sim 1200^{\circ} \mathrm{C}\right)$ for $1 \mathrm{~h}$. The drawing of tempered martensite structure follows the style of F. Abe [29]. For austenization at $800^{\circ} \mathrm{C}$ $(a \rightarrow b \rightarrow e)$, the T91 is at the two phase zone, so significant amount of the grain boundary ferrite is formed. Packets are formed as group of martensite on the same habit plane. In a packet, blocks are typically identified as group of martensite with similar orientation or a combination of two 
different orientations. After quenching, a full martensite structure is not achieved, where polygonal ferrite with undissolved carbides are frequently observed. By austenization at 900$1000^{\circ} \mathrm{C}(\mathrm{a} \rightarrow \mathrm{c} \rightarrow \mathrm{f})$, the T91 steels arrive at gamma phase zone, thus no grain boundary ferrite is observed. Carbide precipitates trapped in martensite lath are identified. By ausforming of T91 at $1000^{\circ} \mathrm{C} \quad(\mathrm{a} \rightarrow \mathrm{c} \rightarrow \mathrm{g} \rightarrow \mathrm{i})$, the T91suffers from variant selection which is different from the unstrained scenario. Martensite with shorter laths is typical in 1000ECAE T91. By austenization at $1100-1200^{\circ} \mathrm{C}(\mathrm{a} \rightarrow \mathrm{d} \rightarrow \mathrm{h})$, the austenite grain coarsens significantly during heating (noted the scale bar is an order of magnitude larger). Except grain boundary packet, no more packet can be identified within the grains although the grain is much larger. Both auto-tempered martensite and bainitic ferrite are identified. $\varepsilon$-carbides align along the same direction in bainite, while $\eta$ - or $\theta$ carbides can precipitate from all the available habit planes in auto-tempered martensite. 

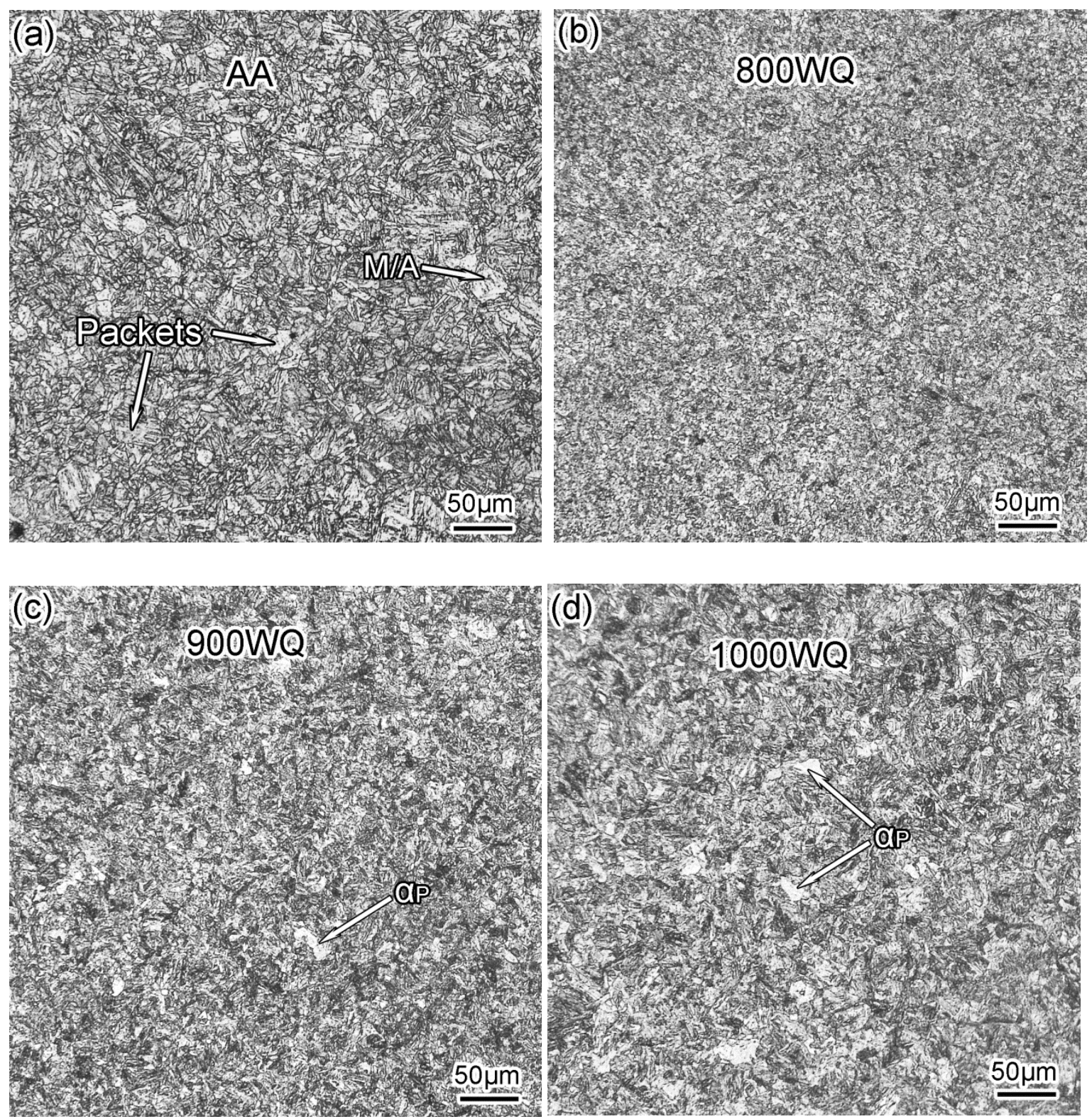


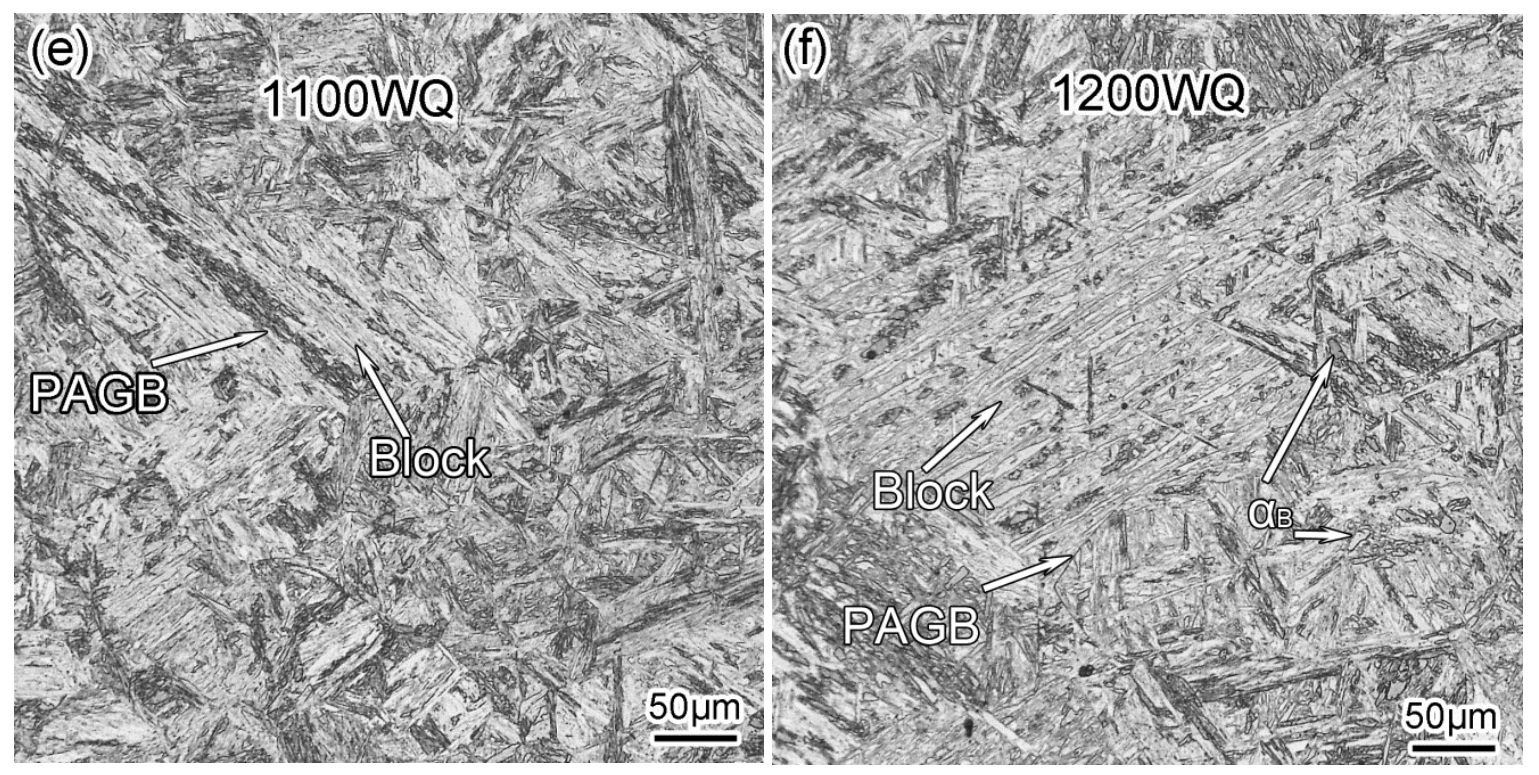

Fig.3. Optical micrographs showing the microstructure of as-annealed (AA) and water quenched (WQ) T91 steel. (a) The AA material is predominantly ferrite with a dispersed equiaxed M/A constituent. Packets are identified as groups of martensite laths with the same habit plane and subdivided blocks. (b) Heat treatment at $800^{\circ} \mathrm{C}$ for $1 \mathrm{~h}$ followed by WQ (800WQ) led to a mixture of $\alpha_{M}^{\prime}$ and $\alpha_{P}$, and GB ferrite $\left(\alpha_{A}\right)$. Heat treatment via (c) 900WQ and (d) 1000WQ resulted in a fully transformed microstructure. The polygonal ferrite $\left(\alpha_{\mathrm{P}}\right)$ is identified as clean grains by arrows. (e) $1100 \mathrm{WQ}$ and (f) $1200 \mathrm{WQ}$ yielded primarily martensite $\alpha_{M}^{\prime}$ and the minor bainite phase $\alpha_{\mathrm{B}}$. A prior austenite grain boundary (PAGB) is identified in the $1100 \mathrm{WQ}$ and 1200WQ specimens. 

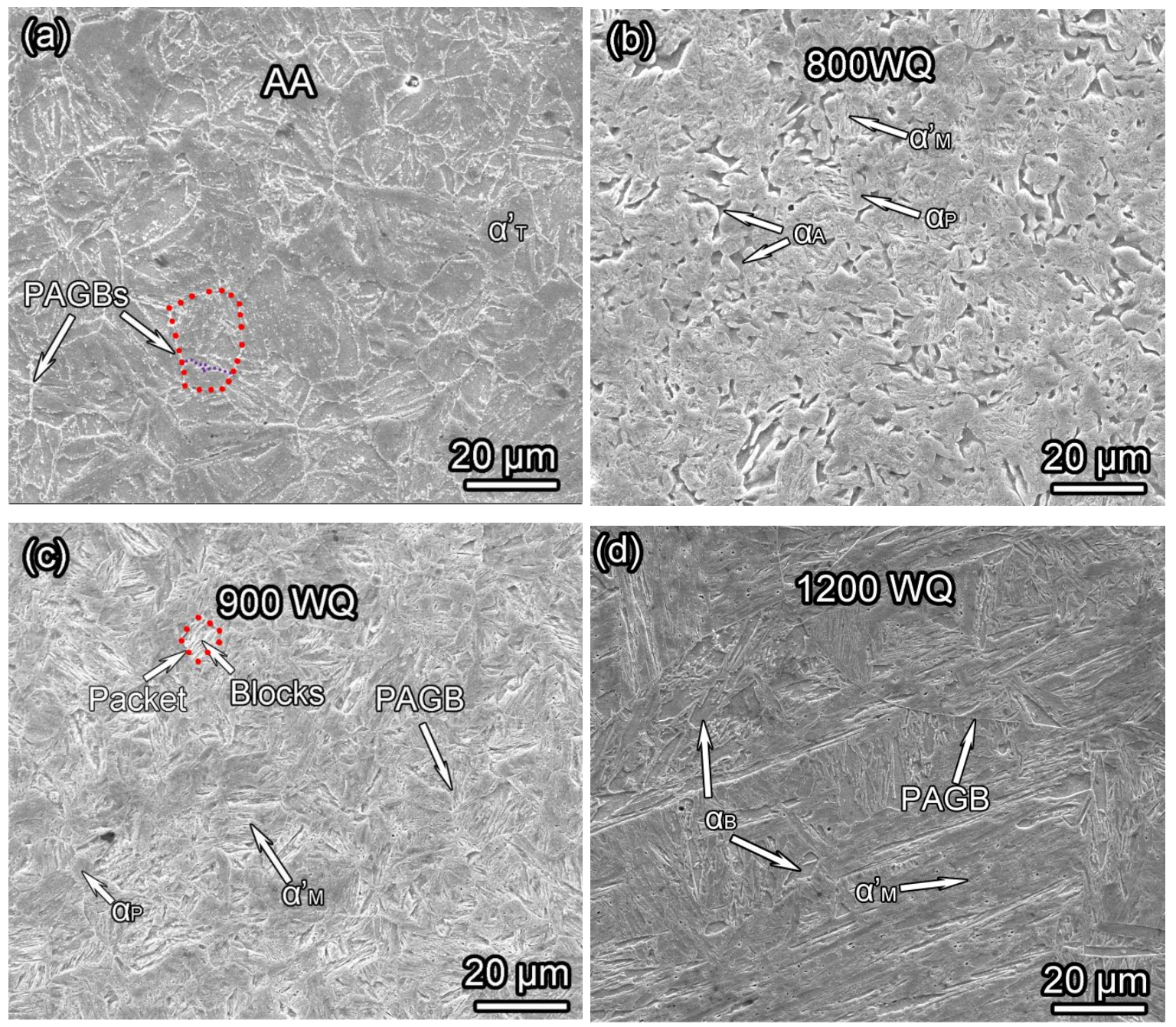

Fig.4. Representative SEM images of AA and WQ T91 steel. (a) The PAGBs are decorated by arrays of carbides (white lines) in the AA condition. Packet boundaries are identified within the PAGBs. (b) Three phases, $\alpha_{\mathrm{A}} \alpha_{\mathrm{P}}$ and $\alpha_{\mathrm{M}}$ are identified in the 800WQ sample. The darker phase is allotriomorphic ferrite or grain boundary ferrite $\left(\alpha_{A}\right)$. The block of martensite $\alpha_{M}^{\prime}$ shows the etched lath feature. The large block phase is $\alpha_{P}$. (c) No allotriomorphic ferrite are observed in the 900WQ T91 specimen. A packet is highlighted with red dots with several blocks inside. (d) Except martensite $\alpha_{M}^{\prime}$, bainitic ferrite $\left(\alpha_{B}\right)$ are also observed in the 1200WQ material. 

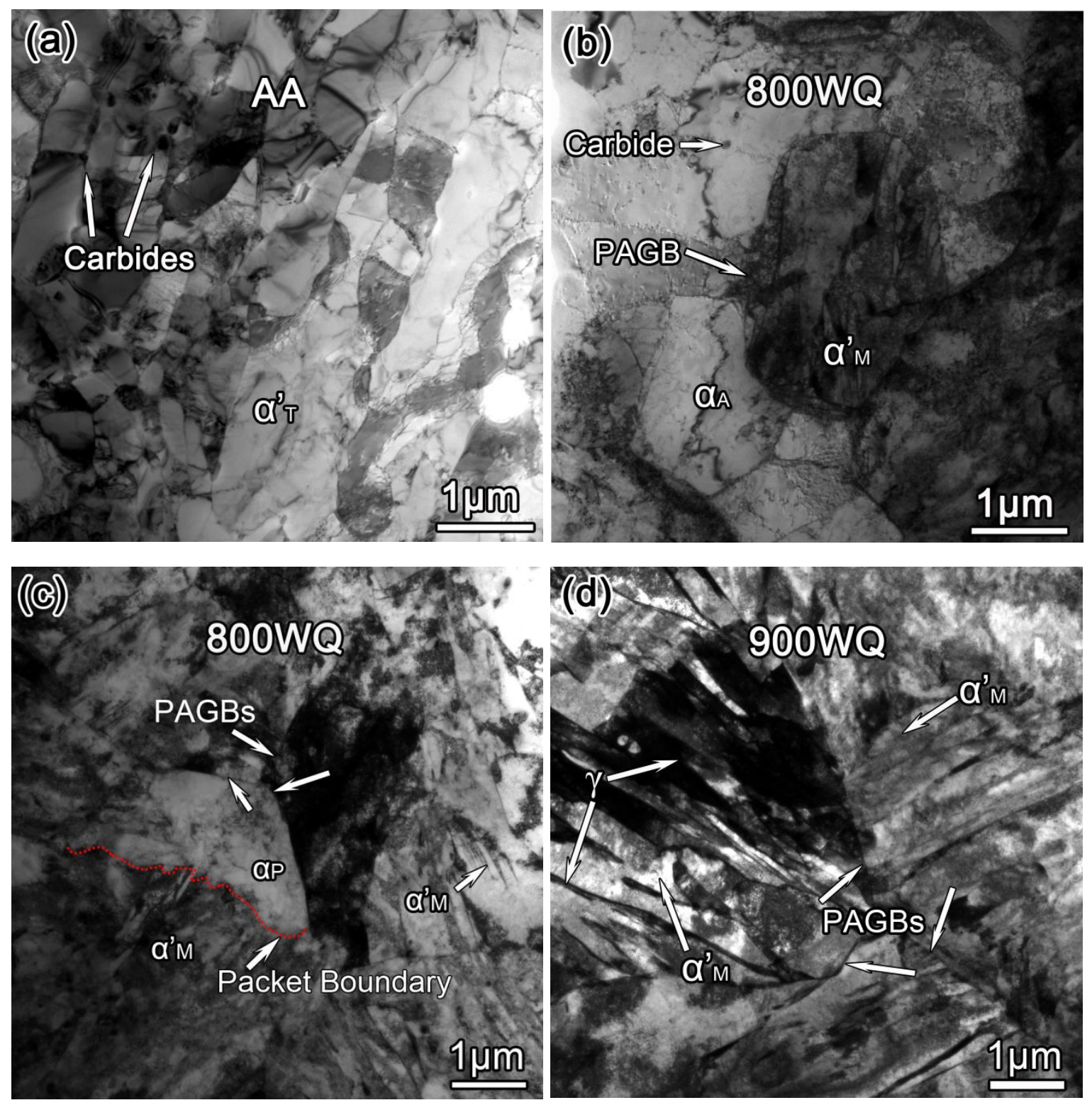

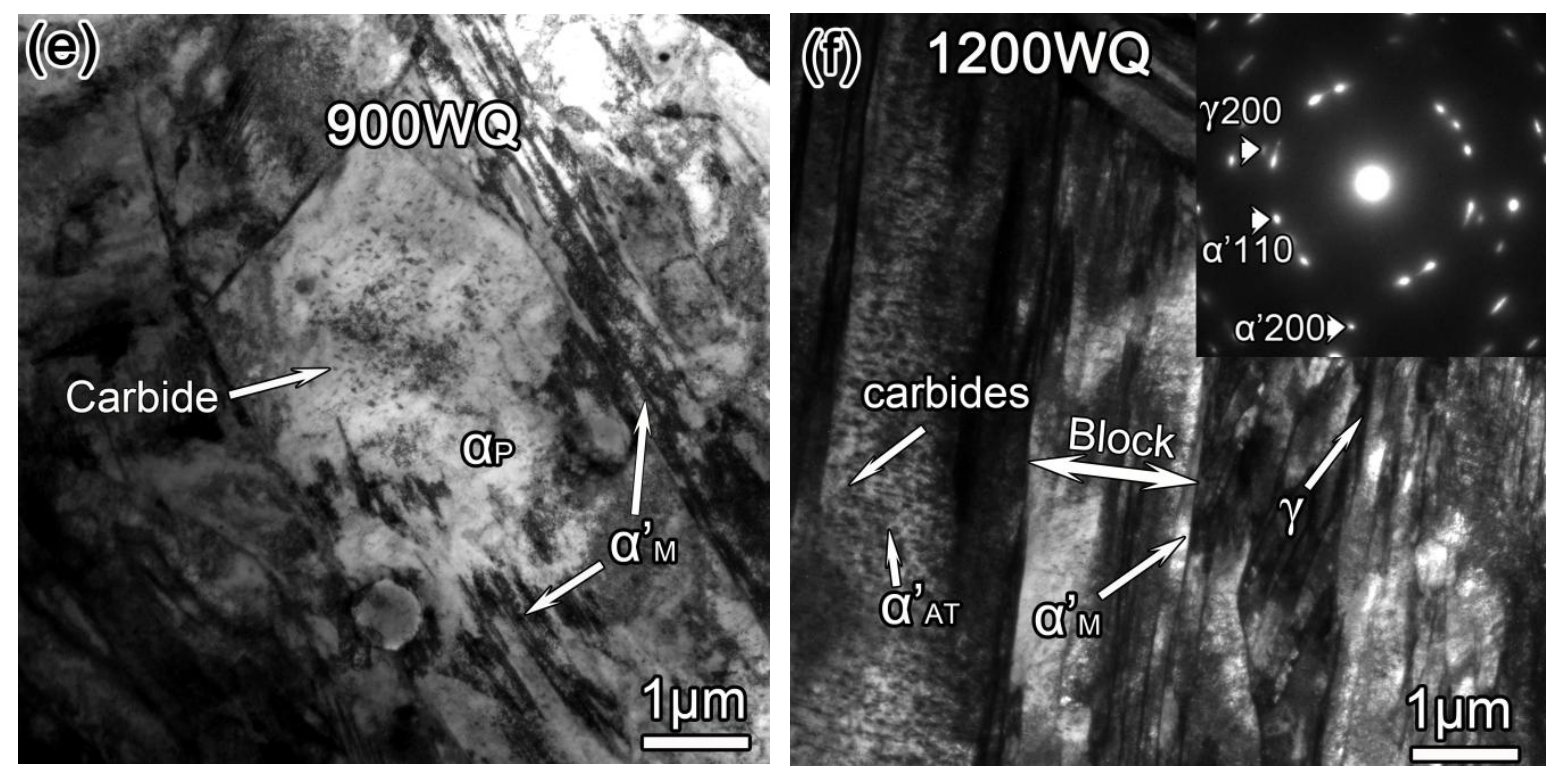

Fig.5. TEM micrographs of AA and WQ T91 steel. (a) AA T91 steel was fully tempered with predominantly the ferrite phase and carbide precipitates. (b) 800WQ T91 exhibits a complex mixture of grain boundary ferrite $\alpha_{A}$ and $\gamma$-transformed structure $\left(\alpha^{\prime}{ }_{M}+\alpha_{P}\right)$. The $\alpha_{A}$ phase is marked following the contours of PAGBs. (c) Some of the $\alpha_{P}$ phase was strengthened by the $\alpha^{\prime}{ }_{M}$ precipitates. Large $\alpha_{P}$ can serve as a single variant and is separated by the packet boundary from martensite during the transformation. (d) Triple junctions of PAGBs in the 900WQ specimen contain a mixture of $\alpha_{M}^{\prime}$ and retained $\gamma$ phase. (e) The $\alpha_{P}$ phases with $\alpha^{\prime}{ }_{M}$ and carbide precipitates are also identified in the 900WQ specimen. (f) Carbides were observed in the martensitic lath structure in 1200WQ materials. Auto-tempered martensite $\alpha^{\prime}$ AT formed during the quenching process. Evidence of retained $\gamma$ phase is present as a thin layer located between two martensitic laths. The inserted selected area diffraction (SAD) pattern reveals the coexistence of the martensite $\alpha_{M}^{\prime}$ and $\gamma$ phases. 


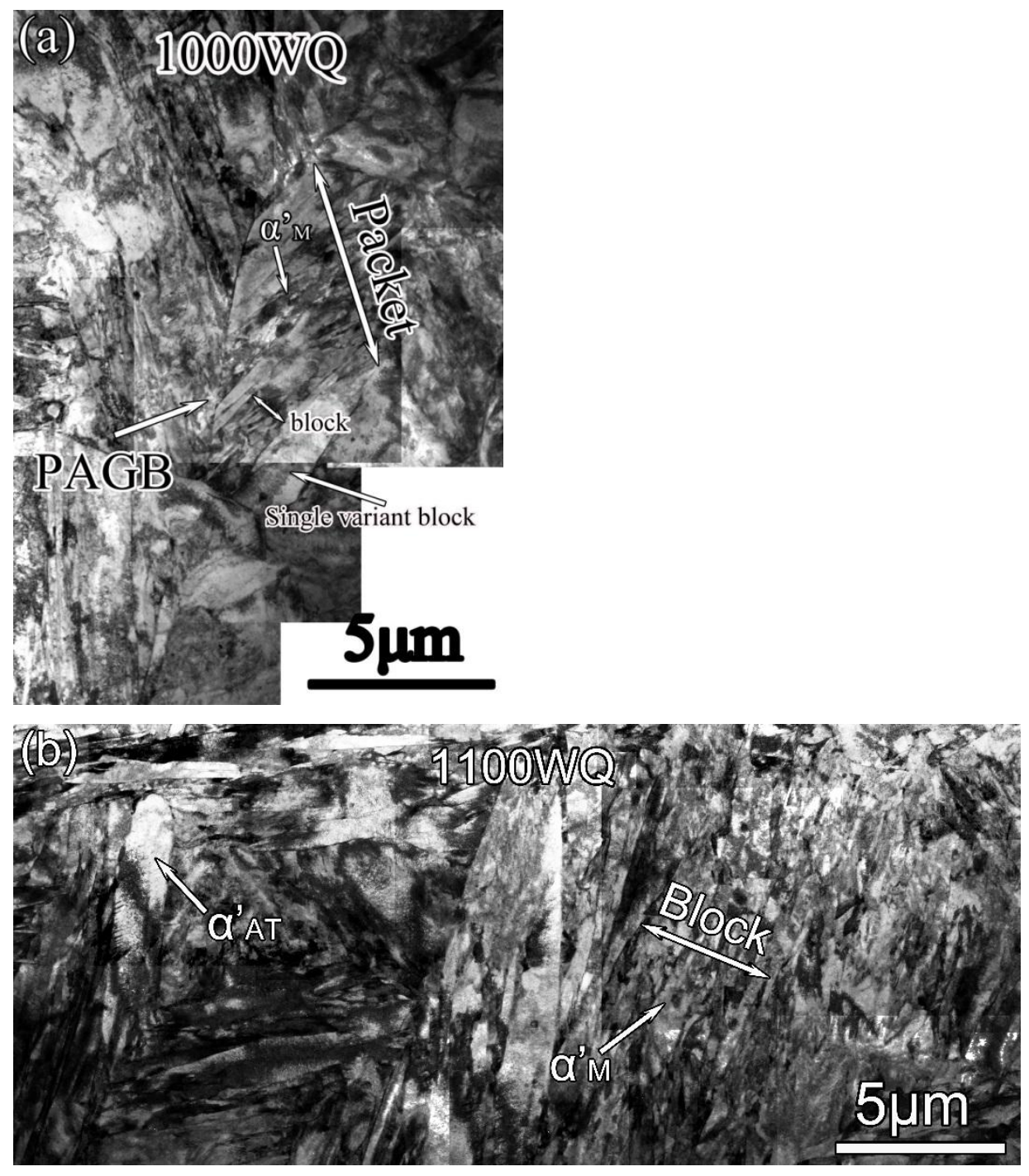

Fig.6 (a) Comparison of $\gamma$ transformed microstructure before and after the coarsening of austenite. (a) A packet was identified at the PAGB in the 1000WQ specimen. A single variant block is noted. (b) No packet can be identified in the 1100WQ specimen. However, blocks are still observed. Both the length and width of blocks increase during the coarsening of prior austenite grains. Auto-tempered martensite $\left(\alpha_{\mathrm{AT}}^{\prime}\right)$ (with carbide precipitates inside the lath) is present. 


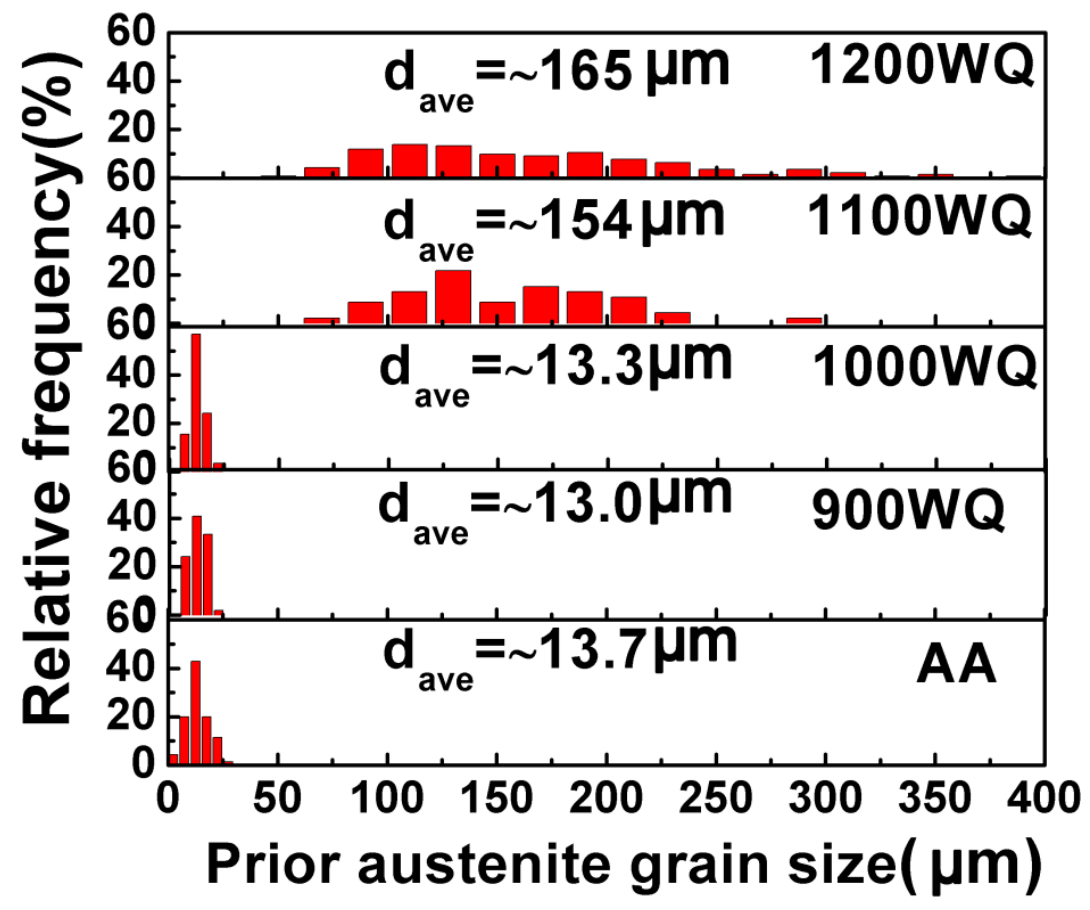

Fig.7 Grain size distributions of prior austenite grains at various WQ conditions show that austenite grains coarsen significantly at $1100^{\circ} \mathrm{C}$ or higher. 

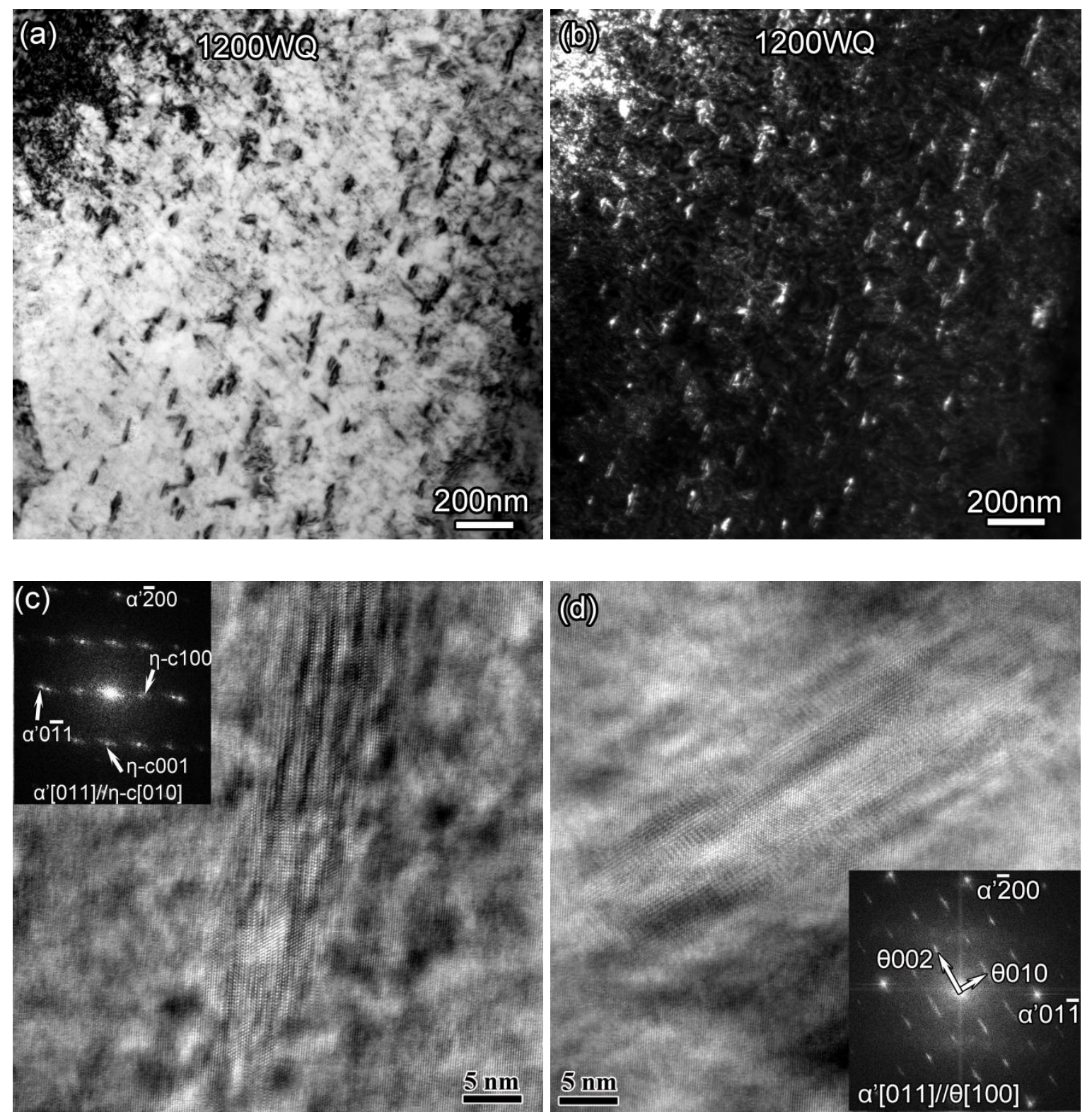

Fig.8 $\eta$-carbide and cementite in WQ T91 steel. (a) Bright field TEM images at the near two beam condition and (b) corresponding weak-beam dark-field images revealing the formation of carbide and cementite. High resolution TEM (HRTEM) micrograph of (c) an $\eta$-carbide and (d) a cementite precipitate. 

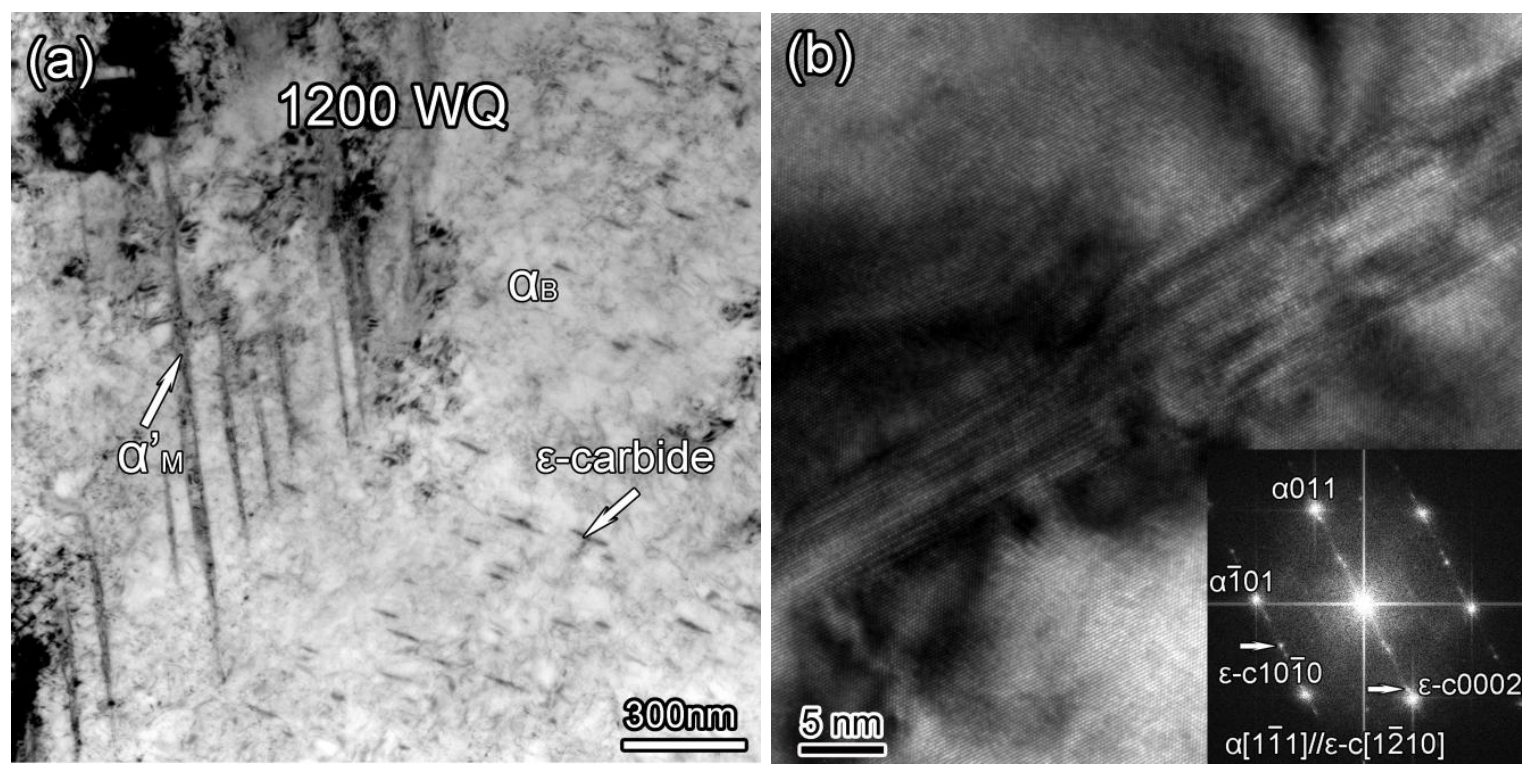

Fig.9 (a) TEM micrograph shows that the 1200WQ specimen contains precipitates, including martensite and $\varepsilon$-carbides, and bainite. (b) HRTEM micrograph of needle shaped $\varepsilon$-carbide with fast Fourier transformation (FFT) inserted in the bottom right corner. 

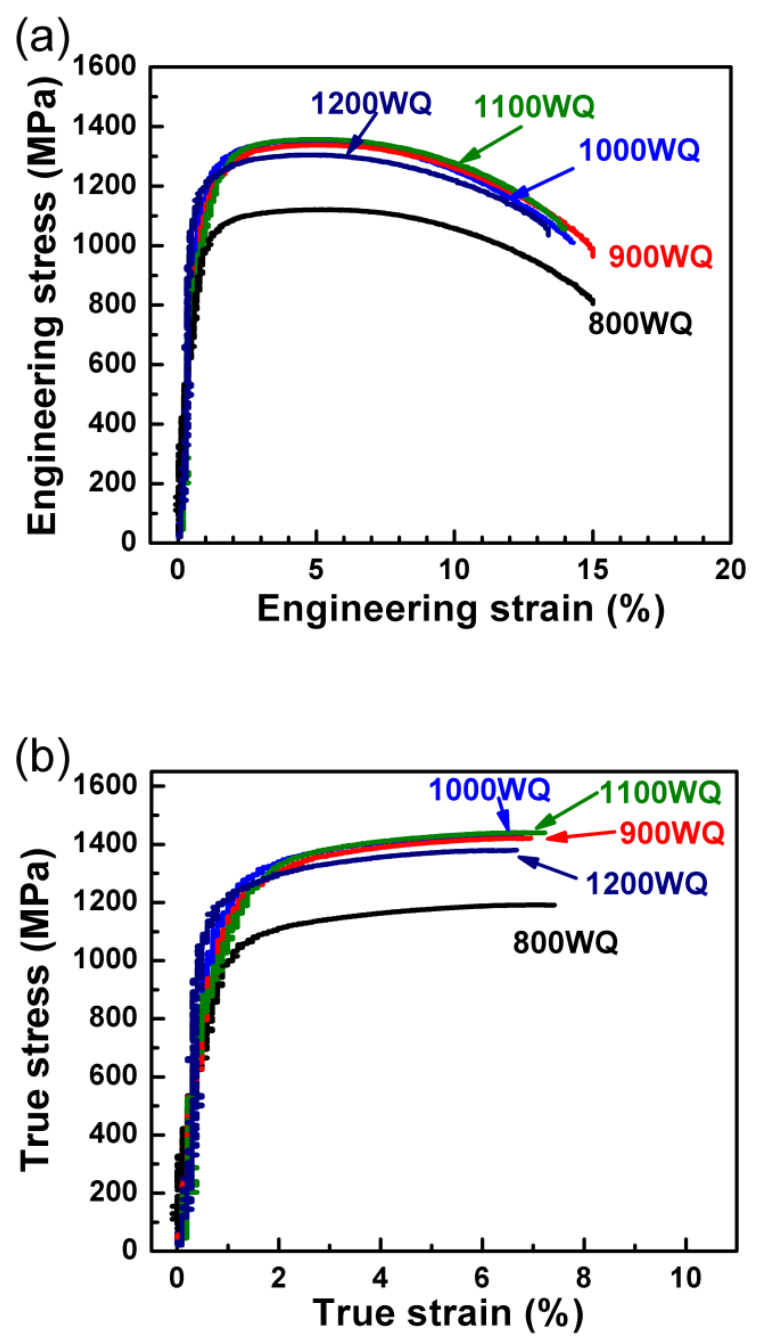

Fig.10 (a) Engineering stress-strain and (b) true stress-true strain curves of WQ T91 alloy tested at room temperature at a constant strain rate of $1 \times 10^{-3} / \mathrm{s}$. Similar flow stress levels are achieved for 900 1200 WQ specimens, which is $200 \mathrm{MPa}$ higher than that of 800WQ T91. 

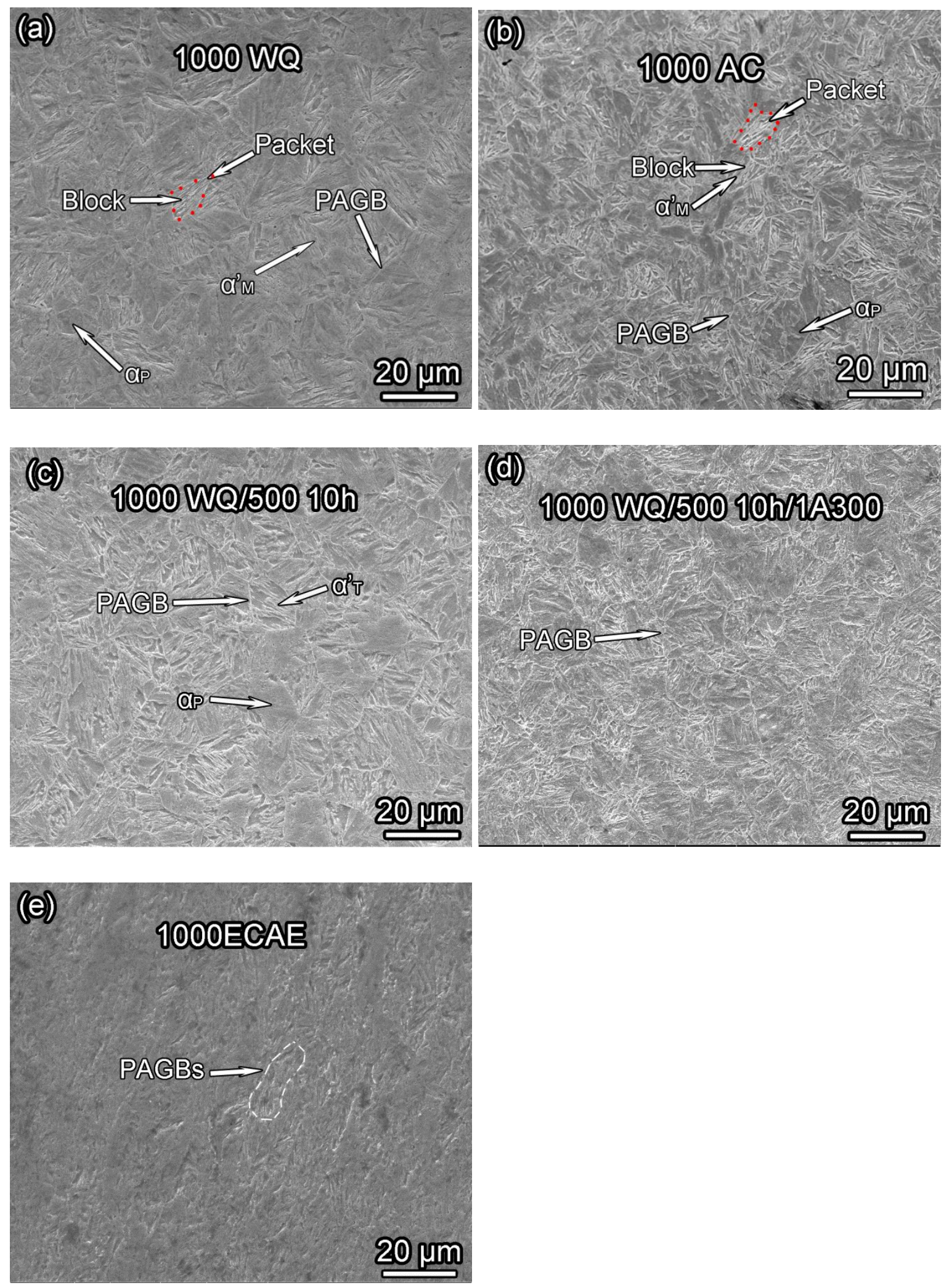

Fig.11 SEM micrographs of T91 after various thermomechanical treatment procedures. (a) Water quenching after normalization at $1000^{\circ} \mathrm{C}$ gives a fully $\gamma$-transformed structure. Both packets and 
blocks are identified. (b) Air cooling after normalization at $1000^{\circ} \mathrm{C}(1000 \mathrm{AC})$ creates a mixture of martensite $\left(\alpha_{\mathrm{M}}^{\prime}\right)$ and polygonal ferrite $\left(\alpha_{\mathrm{P}}\right)$. (c) Tempering of $1000 \mathrm{WQ}$ at $500^{\circ} \mathrm{C}$ for $10 \mathrm{~h}$ yields a tempered martensite structure. The PAGBs become clear due to the formation of GB carbides. (d) ECAE deformation at $300^{\circ} \mathrm{C}$ of tempered $\mathrm{T} 91$ (1000WQ/500C $\left.10 \mathrm{~h} / 1 \mathrm{~A} 300\right)$ induces a deformed martensitic structure and curved PAGBs. (e) Ausforming of T91 steel at $1000^{\circ} \mathrm{C}(1000$ ECAE) leads to shearing of PAGBs. 

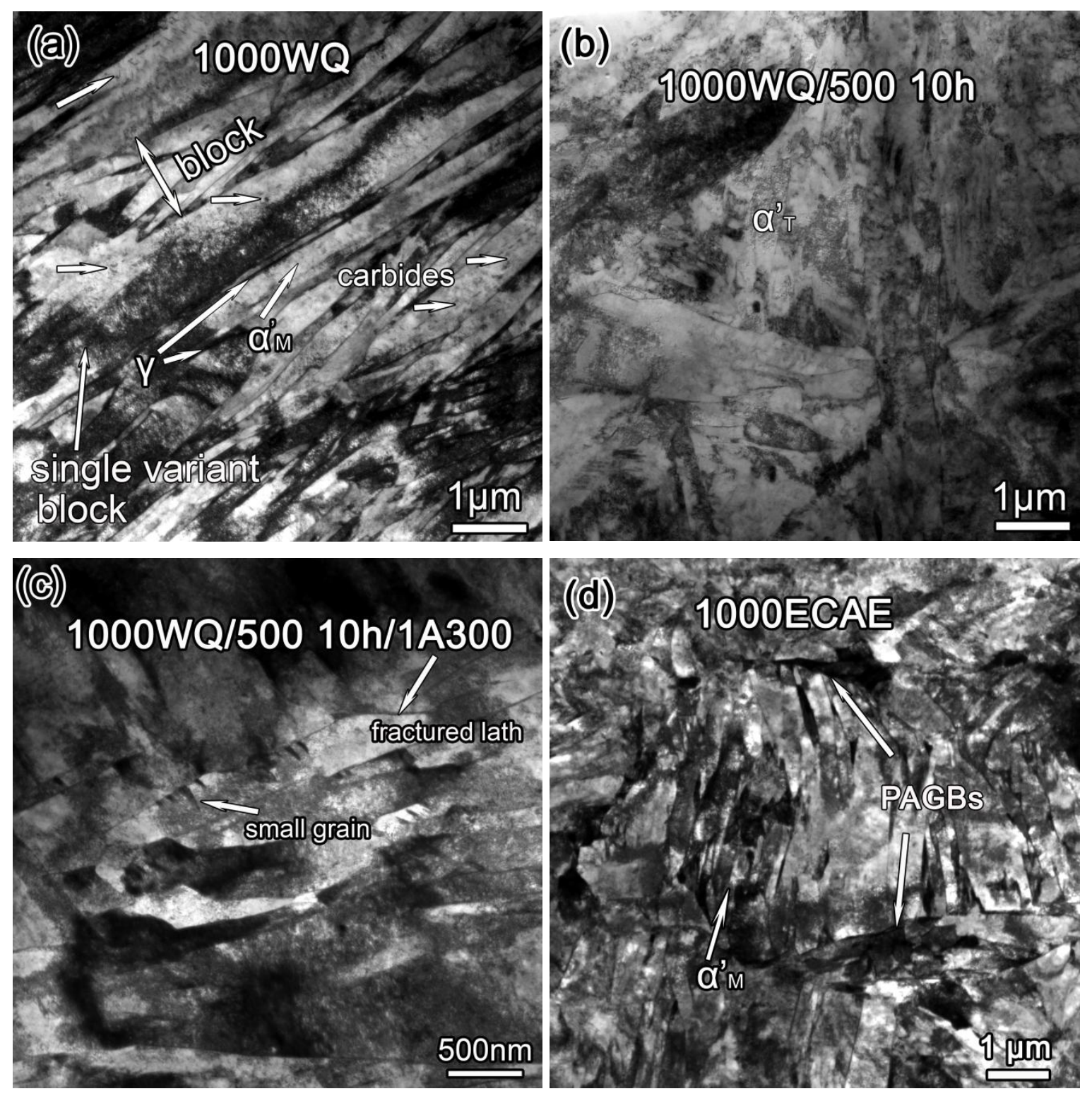

Fig.12 TEM micrographs of T91 processed via various thermomechanical treatments. (a) TEM micrograph of 1000WQ T91 shows a mixture of $\alpha_{M}^{\prime}$ laths, carbides and residual austenite $\gamma$. (b) Heat treatment of the 1000WQ T91 (1000WQ/500 10h) gives rise to a tempered martensite $\alpha_{\mathrm{T}}^{\prime}$ structure. (c) ECAE of the tempered T91 at $300^{\circ} \mathrm{C}(1000 \mathrm{WQ} / 50010 \mathrm{~h} / 1 \mathrm{~A} 300)$ leads to a deformed martensitic structure with a high density of dislocations. (d) ECAE processing at $1000^{\circ} \mathrm{C}$ followed by WQ (1000ECAE) induces a textured fine martensitic structure (examined from the transverse plane). 


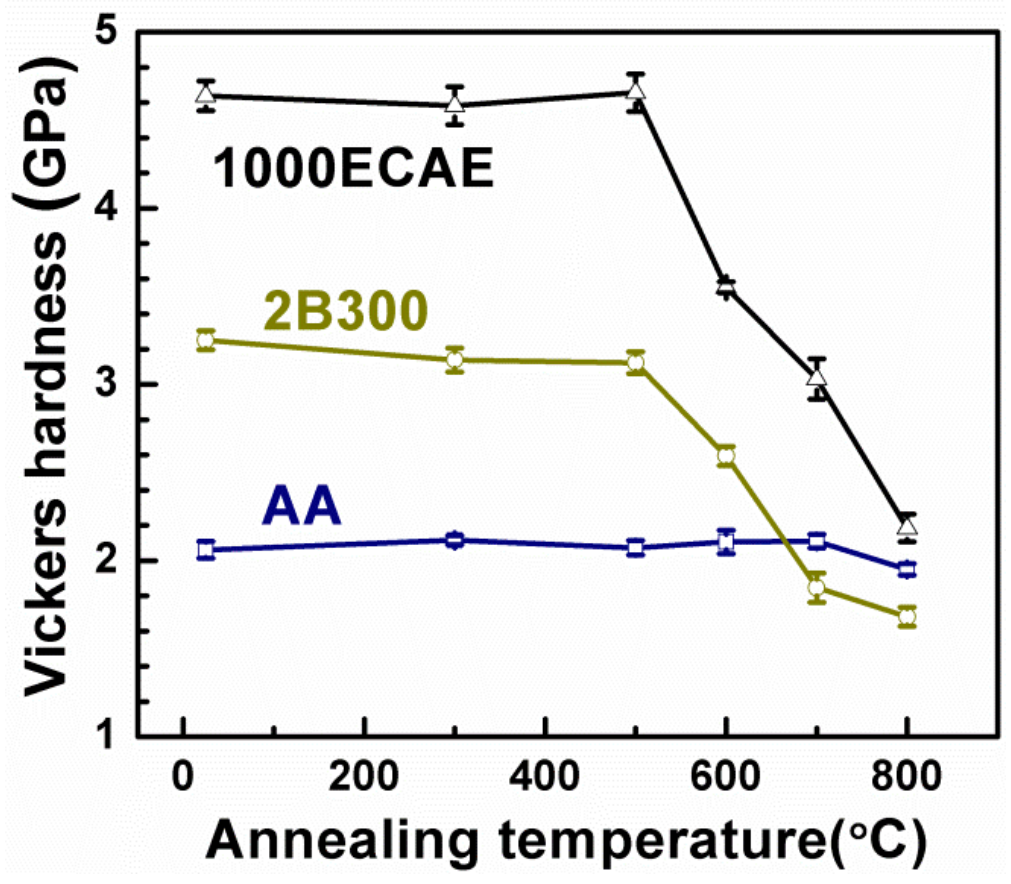

Fig.13 Probing thermal stability of T91 via measurement of hardness evolution with annealing temperature for two representative ECAE processing procedures. The hardness of ECAE processed T91 remained unchanged up to $500^{\circ} \mathrm{C} / 1 \mathrm{~h}$, followed by significant softening at higher annealing temperatures. 

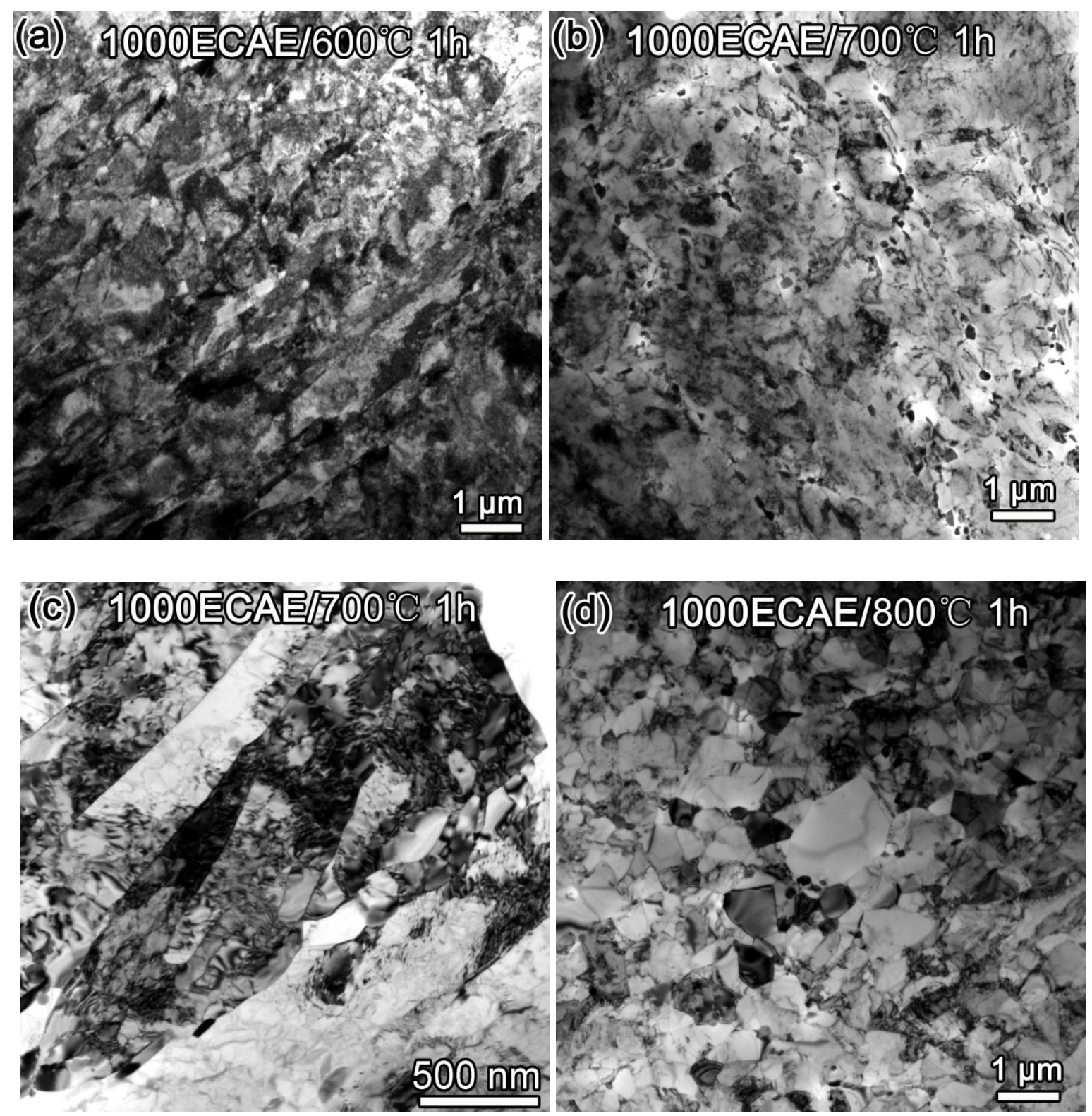

Fig.14 TEM micrographs showing microstructure of 1000ECAE T91 tempered at elevated temperatures. (a) After tempering at $600^{\circ} \mathrm{C}$, tiny carbides forms at martensitic lath boundaries. (b) At $700^{\circ} \mathrm{C}$, carbides coarsen. (c) Tempered martensitic laths around $0.5 \mu \mathrm{m}$ in thickness form by consuming thinner martensitic laths. (d) After tempering at $800^{\circ} \mathrm{C}$, recrystallization and grain growth are evident. 

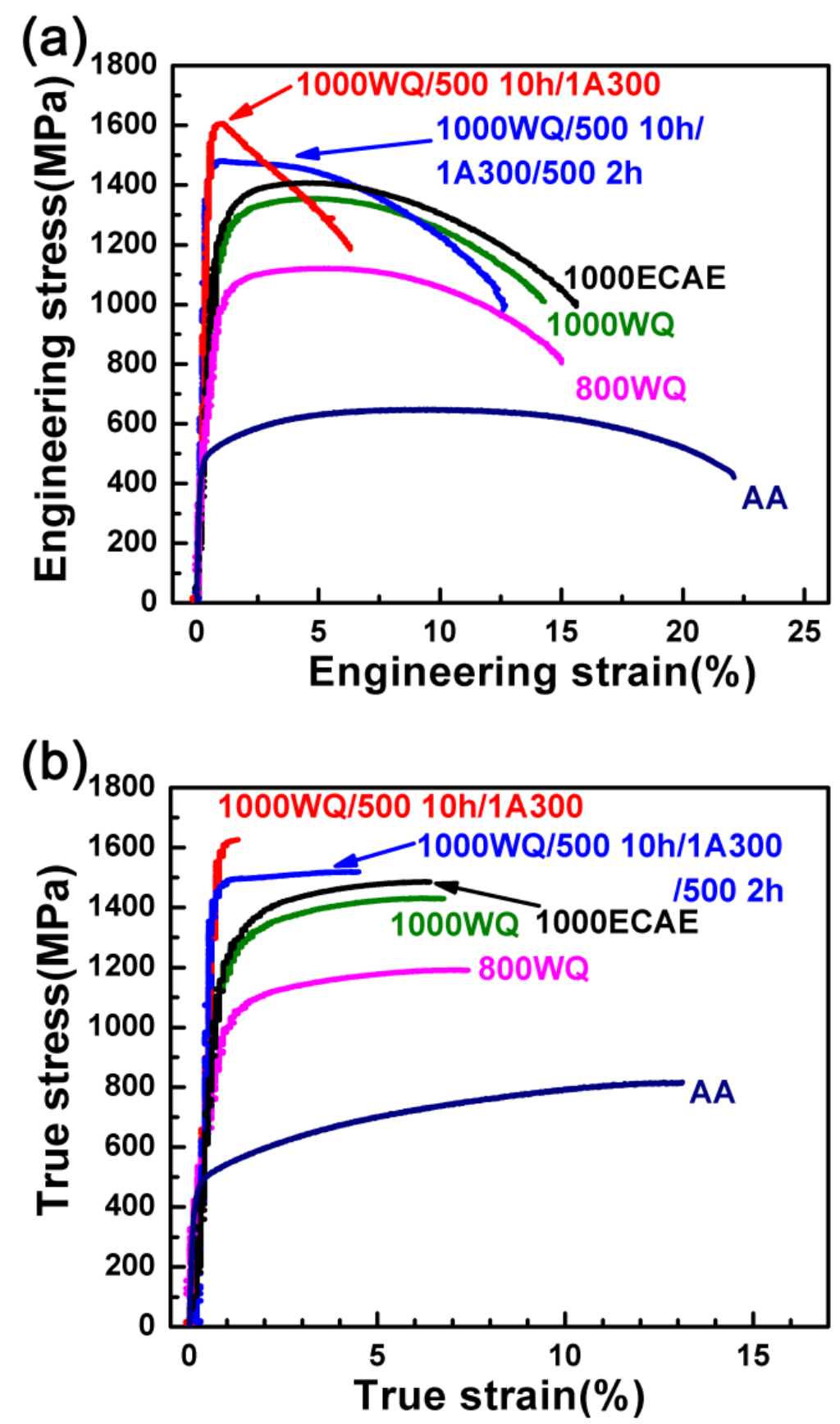

Fig.15 Engineering stress-strain (a) and true stress-true strain curves (b) of T91 alloy after various types of thermomechanical treatments. Compared to 1000WQ T91, high temperature ECAE (1000ECAE) leads to a moderate increase of strength with comparable ductility. ECAE at low temperature (1000WQ/500 10h/1A300) causes a substantial increase in the yield strength with however lower ductility. Heat treatment of the same materials $(1000 \mathrm{WQ} / 500$ $10 \mathrm{~h} / 1 \mathrm{~A} 300 / 500 \mathrm{2h}$ ) results in a combination of high strength and good ductility. 


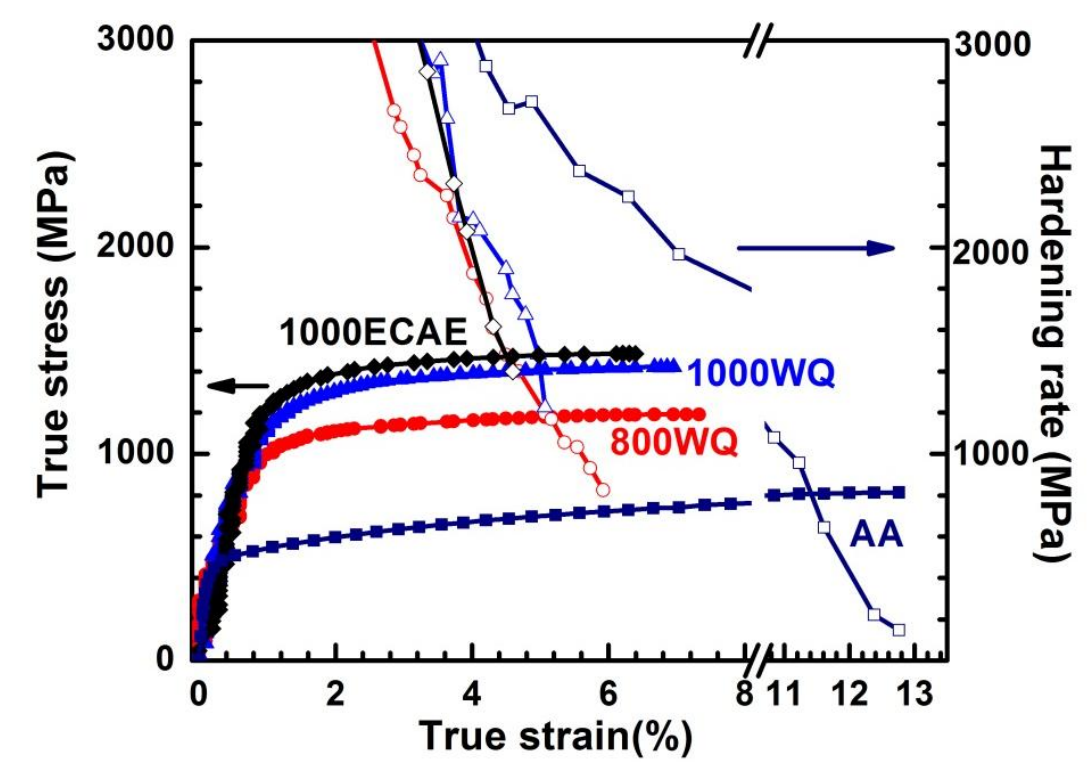

Fig.16 Plots of work hardening rate (open data) and true stress-true strain (solid data points) for several WQ T91 steels and 1000ECAE T91. The intersections between the two sets of curves imply the initiation of plastic instability. AA T91 has excellent uniform elongation. WQ leads to the reduction of uniform elongation to a few percent. 1000ECAE results in a ductility comparable to that of WQ T91.

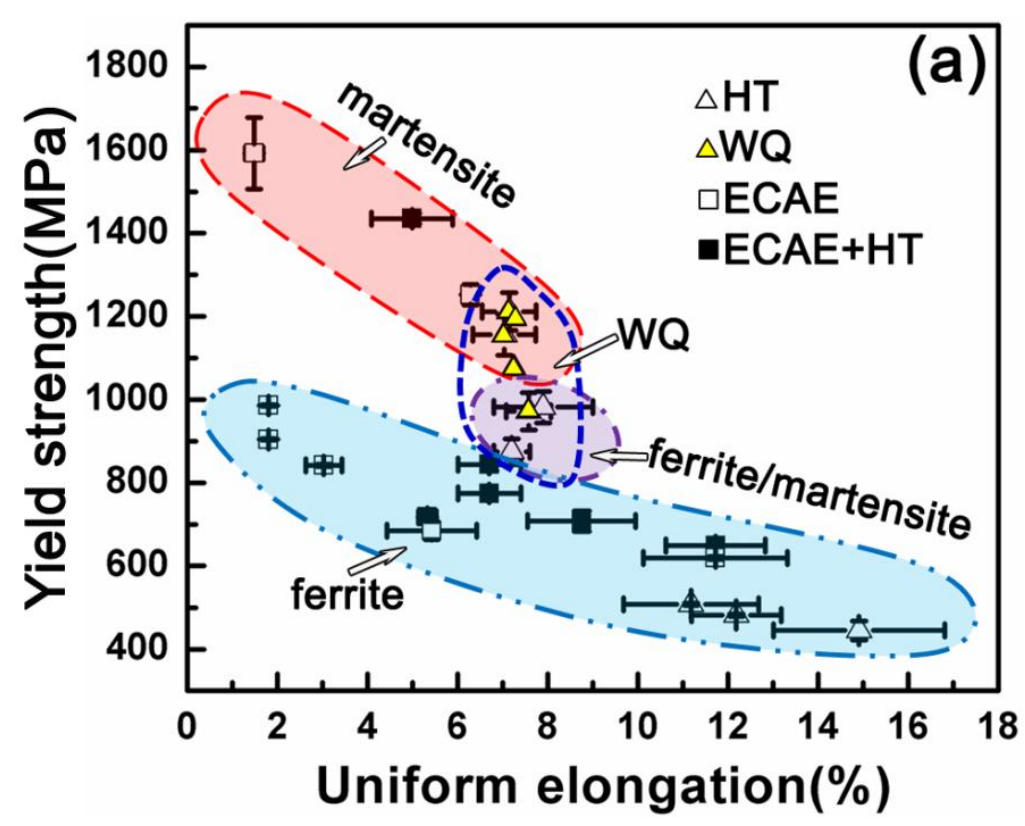




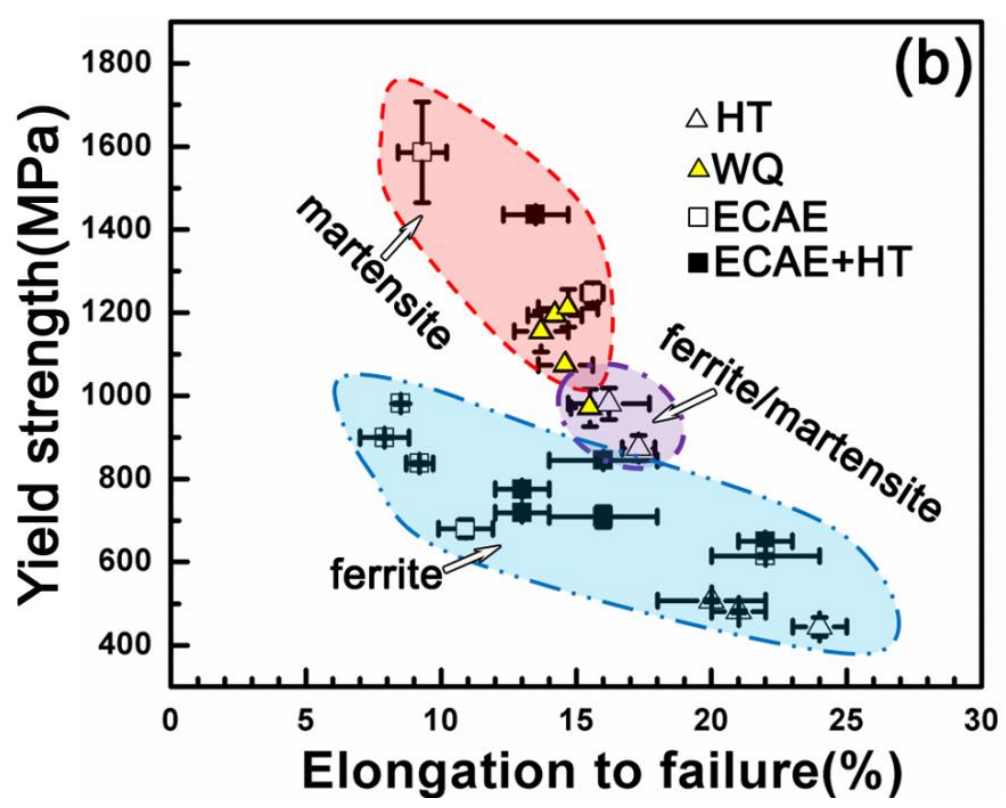

Fig.17. Summary of yield strength-uniform elongation (a) and yield strength-elongation to failure (b) maps for T91 steel subjected to various types of thermomechanical treatments. Three distinctive zones are identified based on the primary phase after processing. In the lower ferrite zone with a banana shape (light blue), ECAE of the ferrite phase T91 steel leads to fine ferrite. Heat treatment at various temperatures was applied to tailor strength and uniform elongation. In general, a higher strength is accompanied by lower ductility. In the upper martensite zone (red shadow), including water quenching from $900-1200^{\circ} \mathrm{C}$, $1000 \mathrm{ECAE}$ or $1000 \mathrm{WQ} / 500$ $10 \mathrm{~h} / 1 \mathrm{~A} 300 / 5002 \mathrm{~h}$ leads to martensite with a combination of high strength and reasonable ductility. In the middle ferrite/martensite regime (purple shadow), the T91 is processed primarily by water quenching from $800^{\circ} \mathrm{C}$ and tempering at $600^{\circ} \mathrm{C}$. Water quenching at an onset temperature in the range of $800-1200^{\circ} \mathrm{C}$ (in yellow triangle) leads to ductile martensite with several percent of uniform elongation because of auto-tempering. Noted: the martensitic region is denoted as a martensite dominated microstructure. 
Tables

Table 1. The chemical composition (wt.\%) of as-received T91 alloy

\begin{tabular}{cccccccccccccc}
\hline $\mathbf{C r}$ & $\mathbf{M o}$ & $\mathbf{V}$ & $\mathbf{M n}$ & $\mathbf{C}$ & $\mathbf{S i}$ & $\mathbf{C u}$ & $\mathbf{N i}$ & $\mathbf{A l}$ & $\mathbf{N b}$ & $\mathbf{N}$ & $\mathbf{P}$ & $\mathbf{S}$ & $\mathbf{F e}$ \\
\hline 9.37 & 0.91 & 0.18 & 0.37 & 0.08 & 0.33 & 0.08 & 0.09 & 0.03 & 0.08 & 0.04 & 0.01 & 0.000 & $\mathrm{Bal}$ \\
6 & 1 & 9 & 9 & 5 & 6 & 0 & 7 & 2 & 0 & 2 & 9 & 8 &. \\
\hline
\end{tabular}

Table 2. Heat treatments and thermomechanical processing conditions of selected samples

\begin{tabular}{ll}
\hline Identifiers & TMT processing condition \\
\hline AA & $\begin{array}{l}\text { annealing of as-received material at } 800^{\circ} \mathrm{C} \text { for } 1 \mathrm{~h}, \text { followed by furnace } \\
\text { cooling }\end{array}$ \\
800WQ & normalizing at $800^{\circ} \mathrm{C}$ for $1 \mathrm{~h}$, followed by water quenching \\
$1000 \mathrm{WQ}$ & normalizing at $1000^{\circ} \mathrm{C}$ for $1 \mathrm{~h}$, followed by water quenching \\
$1000 \mathrm{AC}$ & normalizing at $1000^{\circ} \mathrm{C}$ for $1 \mathrm{~h}$, followed by air cooling \\
$1000 \mathrm{ECAE}$ & one pass ECAE at $1000^{\circ} \mathrm{C}$ and followed by water quenching \\
$1000 \mathrm{WQ} / 500 \mathrm{C} 10 \mathrm{~h}$ & annealing of $1000 \mathrm{WQ}$ sample at $500^{\circ} \mathrm{C}$ for $10 \mathrm{~h}$ \\
$1 \mathrm{~A} 300$ & one pass ECAE at $300^{\circ} \mathrm{C}$ \\
\hline
\end{tabular}

Table 3. Microstructural symbols and nomenclature used for different phases

\begin{tabular}{ll}
\hline symbol & nomenclature \\
\hline$\alpha_{\mathrm{P}}$ & polygonal ferrite in grain interiors \\
$\alpha_{\mathrm{A}}$ & allotriomorphic ferrite/grain boundary ferrite \\
$\alpha_{\mathrm{M}}^{\prime}$ & martensite \\
$\alpha_{\mathrm{T}}^{\prime}$ & tempered martensite \\
$\alpha_{\mathrm{AT}}$ & auto-tempered martensite \\
$\alpha_{\mathrm{B}}$ & bainitic ferrite \\
$\mathrm{M} / \mathrm{A}$ & martensite/austenite constituent \\
$\delta$ & delta ferrite \\
$\gamma$ & retained austenite \\
PAGB & prior austenite grain boundary \\
$\varepsilon-\mathrm{C}$ & epsilon carbide \\
$\eta-\mathrm{C}$ & eta carbide \\
$\theta$ & cementite \\
\hline
\end{tabular}


Table 4. Microstructures and mechanical properties of T91 steel after austenitizing (1 h) and water quenching (WQ)

\begin{tabular}{|c|c|c|c|c|}
\hline $\begin{array}{l}\text { Temperature } \\
\left({ }^{\circ} \mathrm{C}\right)\end{array}$ & Initial phase & Phases after WQ & $\begin{array}{l}\text { Yield stress } \\
\text { (MPa) }\end{array}$ & $\begin{array}{l}\text { Uniform } \\
\text { elongation } \\
(\%)\end{array}$ \\
\hline 800 & $\begin{array}{l}\gamma+\text { undissolved } \alpha+\text { undissolved } \\
\text { carbides }\end{array}$ & $\underline{\boldsymbol{\alpha}}_{\underline{\mathbf{M}}}^{\prime}+\underline{\boldsymbol{\alpha}}_{\underline{\mathbf{A}}}+\alpha_{\mathrm{P}}+$ carbides & $972 \pm 45$ & $7.2 \pm 0.1$ \\
\hline 900 & $\gamma+$ undissolved carbides & $\underline{\boldsymbol{\alpha}}_{\underline{\mathbf{M}}}^{\prime}+\alpha_{\mathrm{P}}+$ carbides & $1127 \pm 74$ & 7 \\
\hline 1000 & $\gamma+$ undissolved carbides & $\underline{\boldsymbol{\alpha}_{M}^{\prime}}+\alpha_{\mathrm{P}}+$ carbides & $1207 \pm 17$ & 7 \\
\hline 1100 & coarse grained $\gamma$ & $\underline{\boldsymbol{\alpha}}_{\underline{\mathbf{M}}}^{\prime}+\alpha_{\mathrm{B}}+$ carbides & $1212 \pm 45$ & $6.9 \pm 0.6$ \\
\hline 1200 & coarse grained $\gamma$ & $\underline{\boldsymbol{\alpha}}_{\underline{\mathbf{M}}}^{\prime}+\alpha_{\mathrm{B}}+$ carbides & $1156 \pm 48$ & $6.8 \pm 0.7$ \\
\hline
\end{tabular}

Table 5. Estimated strengthening contribution (MPa) based on the two models for T91 steel water quenched at $1100^{\circ} \mathrm{C}$

\begin{tabular}{|c|c|c|c|c|c|c|c|c|}
\hline \multirow{2}{*}{$\begin{array}{l}\text { Strengthening } \\
\text { mechansim }\end{array}$} & \multirow[t]{2}{*}{$\sigma_{\mathrm{Fe}}$} & \multirow[t]{2}{*}{$\sigma_{\mathrm{ss}}$} & \multirow[t]{2}{*}{$\sigma_{\mathrm{i}}$} & \multicolumn{2}{|c|}{$\sigma_{\mathrm{H}-\mathrm{P}}$} & \multirow[t]{2}{*}{$\sigma_{\text {disl }}$} & \multirow[t]{2}{*}{$\left(\sigma_{\mathrm{y}}\right)_{\mathrm{cal}}}$. & \multirow[t]{2}{*}{$\left(\sigma_{\mathrm{y}}\right)_{\exp }$} \\
\hline & & & & Lath & Packet & & & \\
\hline SM1 & $\sim 100$ & $\sim 130$ & $\sim 610$ & $\sim 560$ & $\mathrm{~N} / \mathrm{A}$ & $\sim 250$ & $\sim 1650$ & 1210 \\
\hline SM2 & $\sim 100$ & $\sim 130$ & N/A & $\sim 440$ & $\sim 10$ & $\sim 250$ & $\sim 930$ & 1210 \\
\hline
\end{tabular}

Note: $\sigma_{\mathrm{Fe}}$ is the strength of annealed $\mathrm{Fe} ; \sigma_{\mathrm{ss}}$ is the strengthing by substitiaonal atoms; $\sigma_{\mathrm{i}}$ is the strengthening by interistials; $\sigma_{\mathrm{H}-\mathrm{P}}$ is Hall-Petch type strengthening related to the size effect; $\sigma_{\text {disl. }}$ is strenghening by dislocations; $\left(\sigma_{\mathrm{y}}\right)_{\mathrm{cal}}$. and $\left(\sigma_{\mathrm{y}}\right)_{\text {exp. }}$ are the calculated and measured yield strengths respectively. 


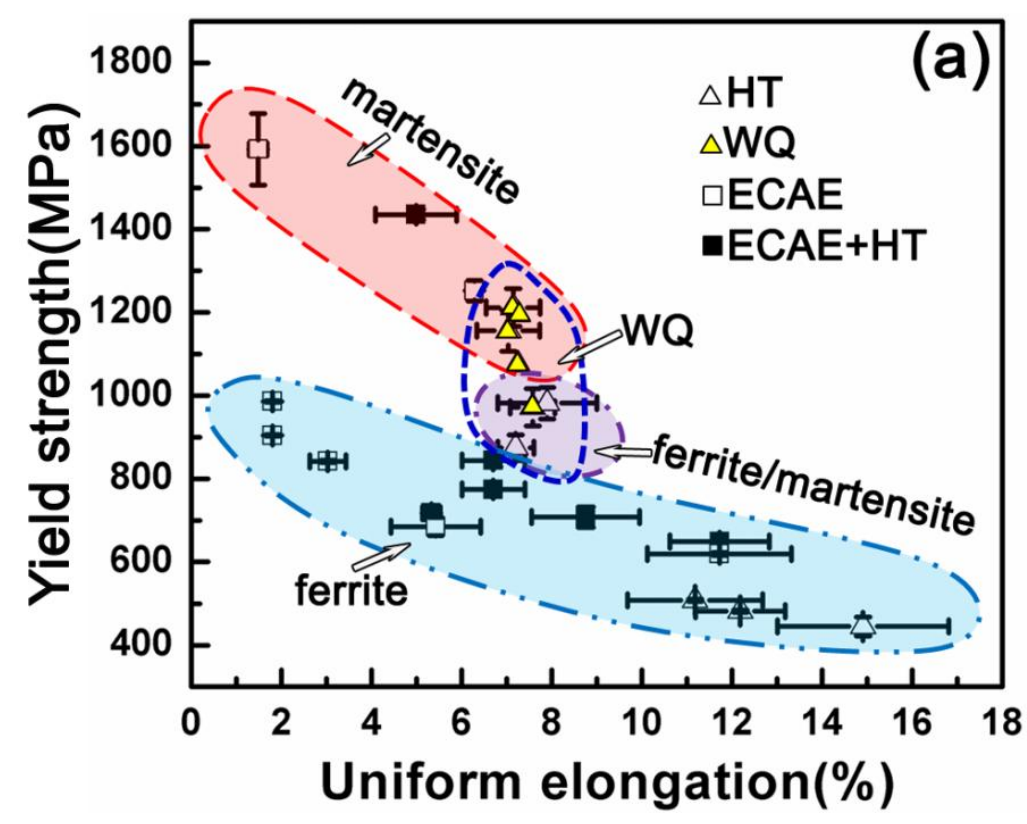

